\title{
Antiplatelet therapy in acute coronary syndromes: focus on ticagrelor
}

This article was published in the following Dove Press journal:

Journal of Blood Medicine

3I August 2010

Number of times this article has been viewed

\author{
Kade Birkeland ${ }^{1,2}$ \\ David Parra ${ }^{1,2}$ \\ Robert Rosenstein ${ }^{2}$ \\ 'Department of Pharmacy, \\ ${ }^{2}$ Department of Medicine, Veterans \\ Affairs Medical Center, West Palm \\ Beach, FL, USA
}

Correspondence: Robert Rosenstein Department of Medicine, Section of Cardiology, Veterans Affairs Medical Center, West Palm Beach, FL, USA

Tel + I 56I 4227456

Fax + I $56 \mid 4225787$

Email robert.rosenstein@va.gov

\begin{abstract}
The use of antiplatelet agents, specifically the thienopyridines, has become a standard of care in the approach to the patient presenting with an acute coronary syndrome. These drugs irreversibly inhibit the platelet by permanently binding to the surface P2Y12 receptor and blocking the downstream fibrinogen cross-linking between platelets, which leads to aggregation and thrombus. However, currently available therapeutic choices are limited by potential interaction with other medications, slow hepatic conversion to active metabolite, genetic resistance, and narrow therapeutic safety margin. In order to overcome these disadvantages, there has been an interest in developing alternatives to thienopyridines. Recent investigations have included ticagrelor, a reversible inhibitor of the P2Y12 platelet receptor, which appears to have overcome several drawbacks of the current thienopyridines. Its unique pharmacokinetic and pharmacodynamic profiles result in an inhibition of platelet aggregation that is rapid, high, consistent, and less susceptible to interpatient variability than currently available P2Y12 inhibitors. In addition, ticagrelor offers a potential mortality advantage not apparent with current agents. Although questions regarding the nature, magnitude, and clinical significance of several observed adverse effects (dyspnea and ventricular pauses) remain unanswered, it appears that ticagrelor may represent a significant advancement over currently available oral antiplatelet agents.
\end{abstract}

Keywords: thienopyridine, clopidogrel, prasugrel, P2Y12, antiplatelet therapy, thrombosis

\section{Introduction}

Coronary heart disease (CHD) remains a significant burden in both developed and undeveloped countries. Worldwide, cardiovascular disease is the major cause of death, resulting in over 17 million deaths per year. ${ }^{1}$ Despite the proclamations by Brown and Goldstein $^{2}$ in 1996 that coronary disease as a major public health problem could end early in the next century, some have voiced concern that people are starting to lose the battle against heart disease. ${ }^{3}$ Recent predictions of a pending "vascular tsunami of pandemic proportions" have appeared in the literature. ${ }^{4}$ Clearly, CHD consumes a significant portion of our limited health care resources.

Acute coronary syndrome (ACS) is often the initial presentation of an individual manifesting coronary artery disease (CAD). The majority of ACS presents as nonST-segment elevation myocardial infarction (NSTEMI), with the remainder as ST-segment elevation myocardial infarction (STEMI), which accounts for $29 \%-47 \%$ of the ACS depending on the registry or database surveyed. ${ }^{5}$ Interestingly, it was recently reported that the incidence of STEMI has dramatically decreased since 1999 , from 133 cases per 100,000 person-years to 50 cases per 100,000 person-years in $2008 .^{6}$ 
ACS typically begins with the rupture or erosion of vulnerable plaque in a coronary artery, which results in the exposure of elements under the endothelial layer, such as collagen or von Willebrand factor, to circulating blood. These ligands trigger a series of responses, including platelet adhesion, activation, and aggregation. ${ }^{7}$ The eventual downstream effect of this process is a coronary thrombus, which may be occlusive (more often associated with a STEMI) or nonocclusive resulting in a NSTEMI. Understanding the natural history of the culprit plaque has been an area of active research, and recent investigations with various imaging modalities hope to discover ways of identifying vulnerable plaque before it ruptures. ${ }^{8}$

Strategies used to reduce the thrombotic risk in ACS include antiplatelet agents (aspirin, thienopyridines, and glycoprotein [GP] IIb/IIIa inhibitors) and antithrombin drugs (unfractionated heparin, low molecular weight heparins, direct thrombin inhibitors, and factor Xa inhibitors). ${ }^{9}$ Of note, the evaluation of oral GP IIb/IIIa inhibitors in patients with ACS was disappointing when results suggested net harm with these agents. ${ }^{10}$

The utility of oral antiplatelet agents in the therapeutic approach to ACS has been established by previous trials of aspirin and thienopyridines. Aspirin, a cyclooxygenase-1selective inhibitor, when given to patients with ACS, results in a significant mortality benefit (Second International Study of Infarct Survival [ISIS-2]). ${ }^{11}$ The use of thienopyridines, which interfere with platelet aggregation by blocking the P2Y12 receptor on the platelet surface, has shown benefit when added to aspirin in this setting. ${ }^{12}$ Thus, the current standard of care for patients who present with ACS is a course of dual antiplatelet therapy, which usually is recommended ideally for up to 1 year following an acute event. ${ }^{13}$

Oral thienopyridines began with ticlopidine, a firstgeneration thienopyridine, which although an effective agent for the irreversible blocking of the platelet P2Y12 receptor, was found to have unfavorable side effects. The use of clopidogrel, a second-generation thienopyridine, almost completely replaced ticlopidine as the preferred P2Y12 inhibitor in ACS. ${ }^{14}$

Although clopidogrel is generally well tolerated, significant limitations remain, and there is an ongoing search for better and safer antiplatelet strategies. Because clopidogrel requires a bioconversion to its active metabolite, there is a delay in the onset of its antiplatelet activity; this can be partially overcome with a higher loading dose. In addition, a certain percentage of the population carries a reduced-function allele of the CYP2C19 gene and subsequently has reduced conversion of prodrug to active metabolite. The irreversible nature of its antiplatelet action also raises concerns for increased bleeding risk and typically results in delays in coronary artery bypass grafting (CABG) or noncardiac operation. ${ }^{15}$ Furthermore, it has been well recognized that some patients will have a poor or variable response to clopidogrel. ${ }^{16}$ Although platelet function testing can identify the in vitro platelet response to P2Y12 inhibitors, there is as yet no general agreement on which platelet assay provides the best method for predicting subsequent clinical events. Therefore, practical utility of such testing in tailoring antiplatelet therapy remains uncertain, pending the results of larger outcome trials. ${ }^{17}$

More recently, a newer third-generation thienopyridine, prasugrel, was evaluated in a large trial and was found to be an effective therapy.$^{18}$ However, concern regarding the higher bleeding risk observed with this drug has resulted in the need for the development of additional novel oral antiplatelet agents. ${ }^{19,20}$ The ideal antiplatelet agent would have a rapid onset and offset of action, not require metabolic conversion via hepatic pathways susceptible to the influence of other drugs or genetic variation, and an acceptable safety profile with a wide therapeutic window.

\section{Pharmacology/mechanism of action}

Ticagrelor is a member of a class of agents known as the cyclopentyl-triazolo-pyrimidines. These agents are relatively resistant to enzymatic degradation by ectonucleotidases, which rapidly degrade adenosine triphosphate (ATP) in vivo. Resistance to this enzymatic degradation is critical because although ATP serves as a natural competitive antagonist to adenosine diphosphate (ADP) at the P2Y12 receptor, it is not a useful pharmacologic approach to P2Y12 antagonism secondary in part to its poor stability. ${ }^{21}$ Efforts to develop stable ATP analogs led to the discovery of cangrelor. Further modifications of this molecule included the elimination of phosphates and a change in the core purine and sugar moieties, leading to the development of ticagrelor. It is not considered an ATP analog because of the changes in the purine and sugar moieties.

Ticagrelor is the most clinically advanced P2Y12 inhibitor in its class, and its chemical structure distinguishes it from the thienopyridines. Similar to the currently available irreversible P2Y12 inhibitors, ticagrelor is orally active and is selective for the P2Y12 receptor. ${ }^{22}$ However, in contrast to thienopyridine agents, it is a reversible inhibitor of the P2Y12, which may afford specific advantages and perhaps disadvantages.

Ticagrelor exerts its action via binding to the P2Y12 receptor in a manner distinct from ADP, resulting in a reversible conformational change of the receptor (Figure 1). The ligand inhibition of the ADP receptor and subsequent signaling affect downstream processes. These include the conversion of cyclic 

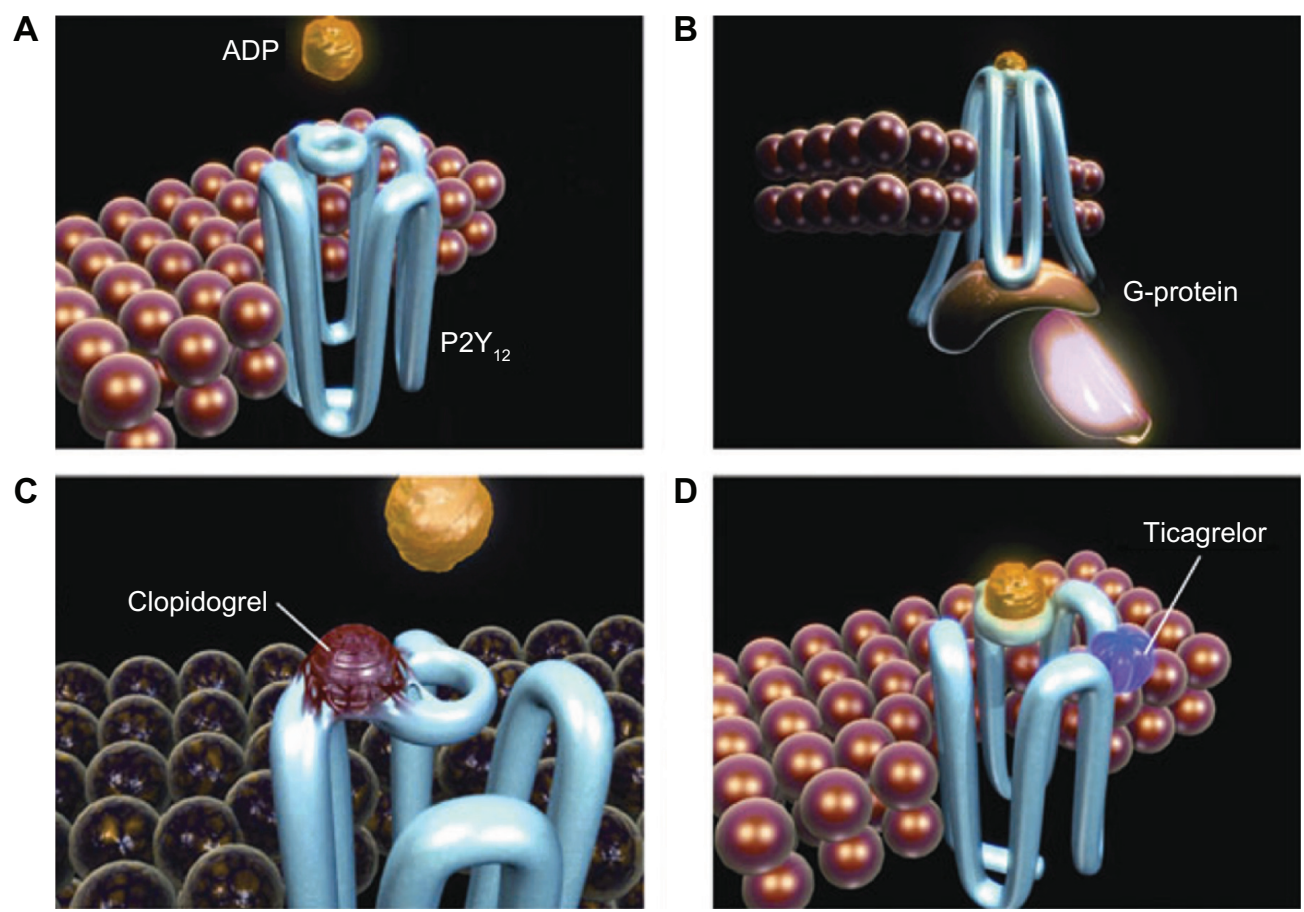

Figure I A and B) ADP binds to the P2Y I2 receptor, resulting in conformational change and G-protein activation. C) Binding of the clopidogrel active metabolite to the P2Y 12 receptor is irreversible, rendering the receptor nonfunctional for the life of the platelet. D) Ticagrelor binds reversibly to P2Y I2 at a site distinct from the ADPbinding site and inhibits ADP signaling and receptor conformational change by "locking" the receptor in an inactive state; the receptor is functional after dissociation of the ticagrelor molecule. ADP can still bind at its binding site, and the degree of receptor inhibition (and inhibition of ADP-induced signaling) is dependant on the concentration of ticagrelor. Copyright (C 2009. Reproduced with permission from Husted S, van Giezen JJ. Ticagrelor: the first reversibly binding oral P2Y I 2 receptor antagonist. CardiovasC Ther. 2009;27:259-274.

Abbreviation: ADP, adenosine diphosphate.

monophosphate from ATP, dephosphorylation of phosphorylated vasodilator-stimulated phosphoprotein (VASP), and activation of phosphoinositide 3-kinase. Inhibition of these processes results in reduced exposure of fibrinogen-binding sites to the GP IIb/IIIa receptor and thereby impairment of platelet aggregation. ${ }^{23}$ Interestingly, ticagrelor inhibits platelet aggregation despite increasing concentrations of ADP, demonstrating that this receptor inhibition is noncompetitive. Therefore, even in the setting of increased ADP concentrations, there would be no reduction in the level of platelet inhibition. Likewise, the effects of ticagrelor on platelet function correlate with plasma drug concentrations. ${ }^{23,24}$ In addition, ticagrelor's effects on nonplatelet-bound ADP receptors may also produce off-target effects on vascular smooth muscle via inhibition of vasoconstriction. Coronary blood flow through inhibition of adenosine uptake by erythrocytes may also be affected. ${ }^{25-27}$ These pleiotropic effects together with ticagrelor's unique reversible inhibition of the P2Y12 receptor may result in both unique advantages and disadvantages.

\section{Pharmacokinetics}

Ticagrelor is rapidly absorbed following oral administration with a median time to peak plasma concentration of
$1.3-2$ hours. ${ }^{28}$ It is metabolized by CYP3A to an equipotent active metabolite (AR-C124910XX) that is present at approximately one-third of the concentration of ticagrelor. ${ }^{29}$ The formation of this active metabolite is rapid, and peak concentrations are reached in a median time of 1.5-3 hours. However, in contrast to the thienopyridines, metabolic activation is not required for inhibition of platelet aggregation (IPA), thus making it less susceptible to clinically significant drug-drug interactions or pharmacogenetic influences. The plasma concentrations (area under the curve [AUC] and maximum plasma concentration $\left.\left[\mathrm{C}_{\max }\right]\right)$ of both ticagrelor and its metabolite are dose proportional and linear when administered as a single dose ranging from 30 to $400 \mathrm{mg}$. When steady-state studies were conducted (measurements at days 14 and 28) with doses of $100 \mathrm{mg}$ twice daily, similar pharmacokinetics were found. However, when administered at long-term doses of $200 \mathrm{mg}$ twice daily or $400 \mathrm{mg}$ once daily, ticagrelor exhibited greater than dose-proportional kinetics with dose-normalized AUCs that were $\sim 50 \%$ more than dose proportional. This suggests that accumulation can occur at higher doses. In none of the aforementioned studies, were the pharmacokinetic variables of ticagrelor or AR-C124910XX affected by age or gender. ${ }^{28,30}$ In addition, there was no effect when administered with a 
high-fat meal. ${ }^{29}$ The terminal plasma half-life of both ticagrelor and its active metabolite, AR-C124910XX, is 6.6-12 and 8.5-10 hours, respectively. This supports twice-daily dosing to maintain a steady-state plasma concentration.

Ticagrelor and AR-C124910XX are further metabolized into inactive metabolites and a glucuronide derivative, which are eliminated in the urine. However, the majority of both ticagrelor and AR-C124910XX are eliminated in the feces, making the need for adjustment in renal disease unlikely. It is unknown whether dose modification or concern is warranted in patients with significant liver disease or in those receiving potent inhibitors or inducers of CYP3A.

\section{Pharmacodynamics}

The pharmacodynamic response to P2Y12 inhibitors can be measured by several different methods. Traditionally, one of the most accepted methods has been light transmittance aggregometry. Preclinical studies of ticagrelor used whole blood impedance aggregometry. In clinical trials, optical aggregometry was adopted as the optimal technique for measuring the IPA. ${ }^{28}$ In single-dose studies ranging from 100 to $400 \mathrm{mg}$, the IPA was dose and time dependent and was nearly complete at 2 hours with a mean IPA of $88 \%-95 \%$ with $20 \mu \mathrm{M}$ of ADP. The IPA gradually declined around 12-hours postdose as plasma concentrations declined, confirming that the IPA was reversible. ${ }^{30}$ Despite this, the IPA 24-hours postdose is still at least equivalent to, and in some cases higher than, clopidogrel $75 \mathrm{mg} .{ }^{30,31}$ With multiple-dose studies, the final extent of IPA with $100 \mathrm{mg}$ twice-daily dosing of ticagrelor is $\sim 90 \%$ at steady state. In patients with ACS receiving low-dose aspirin, a slightly lower dose of ticagrelor $90 \mathrm{mg}$ twice daily produced the final extent of IPA that was $\sim 80 \%$ at 4 weeks. Although the IPA is dose related, doses higher than 90-100 mg twice daily result in only minimal increases in IPA. This suggests that higher doses may not result in any greater efficacy but may expose the patient to greater safety and/or tolerability concerns. Although interpatient variability in IPA response exists with ticagrelor, it is less than that of clopidogrel when a higher initial dose (ie, loading dose) and twice-daily administration are utilized. For example, a 180-mg loading dose of ticagrelor led to a $>70 \%$ IPA at 2 hours in $90 \%$ of patients compared with $16 \%$ for a 600-mg loading dose of clopidogrel. ${ }^{32}$ A recently completed trial in which clopidogrel nonresponders and responders were switched to ticagrelor revealed that ticagrelor overcame nonresponsiveness to clopidogrel. In fact, the resulting antiplatelet effect in nonresponders was found to be the same as in responders. Furthermore, $>98 \%$ of patients had platelet reactivity below the levels associated with ischemic risk while on ticagrelor (vs $44 \%-76 \%$ of those on clopidogrel). ${ }^{33}$ Another unique property of ticagrelor is its reversible inhibition of the $\mathrm{P} 2 \mathrm{Y} 12$ receptor that leads to a more rapid offset of IPA after discontinuation when compared with clopidogrel. In the ONSET/OFFSET study, (Randamized Double-Blind Assessment of the ONSET and OFFSET of the Antiplatelet Effects of Ticagrelor Versus Clopidogrel in Patients with Stable Coronary Artery Disease), ${ }^{34}$ both ticagrelor and clopidogrel were discontinued after 6 weeks. Three days after the drugs were discontinued, the IPA in the ticagrelor group was comparable with the IPA measured at 5 days postclopidogrel. The IPA measured at 5 days postticagrelor discontinuation was similar to the IPA measured at 7 days following clopidogrel withdrawal. The potential clinical implications of this are discussed later.

In summary, the pharmacodynamic effects of ticagrelor as measured by IPA are rapid, high, and consistent. They are of sufficient duration when given twice daily and less susceptible to interpatient variability than currently available P2Y12 inhibitors. The overall clinical benefit (ie, ischemic events vs bleeding) of ticagrelor over currently available oral antiplatelet therapies is an area of current investigation.

\section{Clinical studies}

\section{Phase I trials}

There have been a number of trials conducted in healthy subjects to evaluate the pharmacokinetic or pharmacodynamic effects and general tolerability of ticagrelor and its active metabolite, AR-C124910XX. Table 1 includes a summary of the pertinent phase I trials that directly compare ticagrelor with placebo, clopidogrel, or aspirin..$^{28,34-39}$

\section{Phase II trials}

The phase II clinical trials, Dose confirmation Study assessing anti-Platelet Effects of AZD6140 vs clopidogRel in non-STsegment Elevation myocardial infarction (DISPERSE) and DISPERSE-2, and subsequent substudies evaluated the pharmacokinetic or pharmacodynamic effects, clinical effects, and safety of ticagrelor in patients with stable atherosclerosis and non-ST-segment elevation ACS (NSTE-ACS). ${ }^{29,40}$ A summary of phase II trials is presented in Table 2.

\section{DISPERSE trial}

The DISPERSE trial ${ }^{30}$ was a multicenter, multinational, randomized, double-blind, double-dummy, parallel-group study to assess ticagrelor pharmacokinetic or pharmacodynamic 
Table I Summary of phase I trials with ticagrelor in healthy human subjects

\begin{tabular}{|c|c|c|c|}
\hline $\begin{array}{l}\text { Reference } \\
\text { (patients) }\end{array}$ & $\begin{array}{l}\text { Ticagrelor } \\
\text { (dosing) }\end{array}$ & Comparator & End point \\
\hline $\begin{array}{l}\text { Peters }^{34}(2004) \\
N=13\end{array}$ & $\begin{array}{l}30,100,200,300 \text {, and } \\
400 \mathrm{mg} \text { once daily; } \\
\text { escalating one-time } \\
\text { single dose } \times 8 \text { treatment } \\
\text { periods of } 7 \text { - } d \text { duration }\end{array}$ & Placebo & $\begin{array}{l}\text { Ticagrelor and } \\
\text { AR-CI249I0XX } \mathrm{C}_{\text {max }}, \\
\mathrm{T}_{\text {max }}, \mathrm{AUC}_{0-\infty}, \mathrm{t}_{1 / 2}, \text { platelet } \\
\text { aggregation (maximal } \\
\text { and final inhibition), } \\
\text { bleeding time, adverse } \\
\text { events, vital signs, ECG, } \\
\text { clinical chemistry and } \\
\text { hematology, Holter } \\
\text { monitoring, urinalysis, } \\
\text { examination for petechia }\end{array}$ \\
\hline
\end{tabular}

Main findings

(patients)

$400 \mathrm{mg}$ once daily;

escalating one-time

single dose $\times 8$ treatment

periods of 7-d duration

Peters $^{35}(2006)$

$(\mathrm{N}=46)$
50,100 , and $200 \mathrm{mg}$ once daily or twice daily; 200, 300, 400, and $600 \mathrm{mg}$ once daily; or $50,100,200$, and $300 \mathrm{mg}$ twice daily; ascending dosing every $5 \mathrm{~d}$
Clopidogrel 300-mg LD, then $75 \mathrm{mg}$ once daily; $14 \mathrm{~d}$
$\mathrm{C}_{\max }, \mathrm{T}_{\max }, \mathrm{C}_{\mathrm{ss}}, \mathrm{AUC}$, $\mathrm{t}_{1 / 2}$, platelet aggregation (ticagrelor day 5 , clopidogrel days I and 14), mean bleeding time, vital signs, ECG, laboratory tests
Ticagrelor exhibits rapid and linear absorption with rapid formation of AR-CI24910XX (active metabolite) and dose-proportional $C_{\max }$ and AUC (ticagrelor and AR-CI249 IOXX): mean range of ticagrelor parameters $-C_{\max }$ $(\mathrm{ng} / \mathrm{mL}), \mathrm{I}$ | I-27I I; $\mathrm{t}_{\max }(\mathrm{h}), \mathrm{I} .5 ; \mathrm{AUC}_{0-\infty}$ (ng h/mL), 1005-18,547; CL/F (mL/min kg), 6.7-5; $\mathrm{t}_{1 / 2}$ (h), 7.3-8.9; mean range of AR-CI249I0XX parameters $-C_{\text {max }}(\mathrm{ng} / \mathrm{mL})$, 42-7I3; $\mathrm{t}_{\text {max }}(\mathrm{h}), \mathrm{I} .5-3 ; A \cup \mathrm{C}_{0-\infty}(\mathrm{ng} \mathrm{h} / \mathrm{mL})$, 376-6577; $\mathrm{t}_{1 / 2}(\mathrm{~h}), 8.5-10.1$

Ticagrelor ( $\geq 30 \mathrm{mg}$ ) platelet inhibition (IPA) was dose related, rapid, sustained up to $4 \mathrm{~h}$ (plateau effect, 100-400 mg near 100\% IPA), and reversible at 12-24 h: $2 \mathrm{~h}$ (mean 78\%-95\%; final extent with $20 \mu \mathrm{M}$ ADP), $4 \mathrm{~h}(65 \%-95 \%$; final extent with $20 \mu \mathrm{M}$ ADP), 12 h (35\%-89\%; final extent with $20 \mu \mathrm{M}$ ADP), and $24 \mathrm{~h}$ ( $10 \%-85 \%$; final extent with $20 \mu \mathrm{M}$ ADP)

Subjects experienced prolonged bleeding time after administration of ticagrelor independent of dose. Bleeding time varied amongst and between subjects: mean bleeding time increases $2 \mathrm{~h}$ postdose ( $100-400 \mathrm{mg}$; 2.5-7.4 fold) and $4 \mathrm{~h}$ postdose ( $100-400 \mathrm{mg}$; I.9-3.8 fold) Adverse events: no apparent dose relationship, I 3 with $\geq$ I adverse event, and mild purpura most common (placebo 55\%; 30 mg 20\%-40\%; 100 mg 60\%-67\%; 200 mg 63\%; 300 mg 38\%; 400 mg 29\%) Study treatment discontinuation: I subject experienced syncope $10 \mathrm{~d}$ after ticagrelor administration and felt unrelated to treatment

Ticagrelor demonstrated rapid onset with dose-dependent $C_{\max }$ and AUC. Ticagrelor pharmacokinetic parameters: $T_{\max }, 1.5-3 \mathrm{~h}$; $\mathrm{C}_{\mathrm{ss}}, 2-3 \mathrm{~d}$; and mean $\mathrm{t}_{\mathrm{l} / 2}, 6-13 \mathrm{~h}$ Ticagrelor inhibited platelet aggregation in a dose- and time-dependent manner (all doses) and to a greater degree with less variability than clopidogrel (doses $\geq 100 \mathrm{mg}$ twice daily and $\geq 300 \mathrm{mg}$ once daily): IPA $97 \%-100 \%$ throughout entire dosing; interval (ticagrelor $300 \mathrm{mg}$ twice daily); $4 \mathrm{~h}$ mean IPA $67 \%$; range $0 \%-100 \%$ and $90 \%$; range 13\%-100\% (clopidogrel day I and day 14) Mean bleeding time: placebo (I.I-I.2 fold), ticagrelor (I.I-3.3 fold), and clopidogrel (I.5-I.9 fold)

Adverse events: no dose-related adverse events or clinically important effects on vital signs, ECG, laboratory tests reported

(Continued) 
Table I (Continued)

\begin{tabular}{|c|c|c|c|c|}
\hline $\begin{array}{l}\text { Reference } \\
\text { (patients) }\end{array}$ & $\begin{array}{l}\text { Ticagrelor } \\
\text { (dosing) }\end{array}$ & Comparator & End point & Main findings \\
\hline $\begin{array}{l}\text { Butler }^{36}(2007) \\
(\mathrm{N}=14)\end{array}$ & $\begin{array}{l}50 \mathrm{mg} \text { twice daily }(\mathrm{I}-5 \mathrm{~d}) ; \\
200 \mathrm{mg} \text { twice daily }(6-9 \mathrm{~d}) ; \\
200 \mathrm{mg} \text { once daily }(\mathrm{I} 0 \mathrm{~d}) ; \\
\text { and } \mathrm{I} 0-\mathrm{d} \text { treatment } \times \\
2-\text { period } \mathrm{I}=(+) \text { aspirin } \\
\text { and period } 2=(-) \text { aspirin }\end{array}$ & $\begin{array}{l}\text { Aspirin } 300 \mathrm{mg} \\
\text { once daily; } \\
10 \mathrm{~d}\end{array}$ & $\begin{array}{l}\mathrm{C}_{\max }, \mathrm{AUC} \text {, platelet } \\
\text { aggregation, tolerability }\end{array}$ & $\begin{array}{l}\text { Pharmacokinetics for ticagrelor and } \\
\text { AR-CI } 249 \text { IOXX (active metabolite): } C_{\max } \text { and } \\
\text { AUC for all ticagrelor doses; unaffected } \\
\text { by concomitant; and aspirin therapy } \\
\text { Pharmacodynamics of ticagrelor: rate, extent, } \\
\text { and duration of IPA; unaffected by } \\
\text { concurrent aspirin; aspirin increased } \\
\text { collagen-induced platelet aggregation } \\
\text { (eg, ticagrelor } 200 \text { mg alone } 20 \% \text { and } \\
\text { ticagrelor } 200 \text { mg with aspirin } 76 \% \text { ) } \\
\text { reflecting combined antiplatelet effects } \\
\text { Tolerability: all doses tolerated with or } \\
\text { without concurrent aspirin therapy }\end{array}$ \\
\hline $\begin{array}{l}\text { Butler }^{37}(2008) \\
(\mathrm{N}=6)\end{array}$ & $\begin{array}{l}\text { Single } 200 \mathrm{mg}^{14} \\
\text { C-ticagrelor suspension }\end{array}$ & Placebo & $\begin{array}{l}\text { Radioactive dose } \\
\text { recovered percent, mean } \\
\text { radioactivity, plasma or } \\
\text { blood ratio, major } \\
\text { radioactive components } \\
\text { by location, mean total } \\
\text { amounts unchanged } \\
\text { in urine }\end{array}$ & $\begin{array}{l}\text { Ticagrelor was extensively metabolized with } \\
\text { total recovery of radioactive dose: average } \\
84.3 \% \text { ( } 26.5 \% \text { in urine and } 57.8 \% \text { in feces) } \\
\text { Ticagrelor radioactivity restricted primarily to } \\
\text { plasma space: mean radioactivity; plasma } \\
\text { or blood ratio I.69. } \\
\text { Major radioactive components in feces and } \\
\text { plasma: AZD6I } 40 \text { and AR-CI } 249 \text { I0XX } \\
\text { (active metabolite) Major radioactive } \\
\text { components in urine: AR-CI339I3XX and } \\
\text { its glucuronide conjugate } \\
\text { Exposure to active compounds unlikely affected } \\
\text { by renal impairment as determined by mean } \\
\text { total amounts unchanged AZD6 I } 40 \text { and } \\
\text { AR-CI } 249 \text { I0XX excreted in urine: } 0.02 \% \text { and } \\
0.04 \% \text { of total dose }\end{array}$ \\
\hline $\begin{array}{l}\text { Butler }^{38}(2008) \\
(N=48)\end{array}$ & $\begin{array}{l}50,100,200,300, \\
400, \text { and } 600 \mathrm{mg} \\
\text { once daily or twice } \\
\text { daily; } 14 \mathrm{~d}\end{array}$ & $\begin{array}{l}\text { Clopidogrel } \\
300-m g \\
\text { LD, then } \\
75 \text { mg once } \\
\text { daily; I } 4 \text { d }\end{array}$ & $\begin{array}{l}\text { Ticagrelor and } \\
A R-C I 24910 \times X C_{\max } \\
T_{\max }, A C_{0-\infty}, t_{1 / 2} \\
\text { ticagrelor and clopidogrel } \\
\text { platelet aggregation }\end{array}$ & $\begin{array}{l}\text { Ticagrelor exhibited rapid absorption with } \\
\text { dose-proportional } C_{\text {max }} \text { and AUC ticagrelor and } \\
\text { AR-CI249IOXX across all doses: mean } \mathrm{T}_{\text {max' }} \\
\text { I.5-3 h; mean accumulation ratios, I.2-I.8 } \\
\text { Ticagrelor ( } \geq 100 \mathrm{mg} \text { twice daily, } 300 \mathrm{mg} \text { once } \\
\text { daily) inhibited platelet aggregation over the } \\
\text { entire dosing interval to a greater degree, with } \\
\text { less variability than clopidogrel. Twice-daily dose } \\
\text { of ticagrelor was more effective than the once } \\
\text { daily: ticagrelor trough mean IPA 93\%-99\% } \\
\text { vs clopidogrel } 70 \% \\
\text { Adverse events: no safety or tolerability } \\
\text { issues reported }\end{array}$ \\
\hline $\begin{array}{l}\text { a Teng }^{39}(2008) \\
(N=N A)\end{array}$ & $\begin{array}{l}900-1260 \mathrm{mg} \\
\text { once daily; escalating } \\
\text { one-time single } \\
\text { dose } \times 8 \text { treatment } \\
\text { periods of } 7 \text { - } d \text { duration }\end{array}$ & None & $\begin{array}{l}\text { Ticagrelor and } \\
\text { AR-CI249I0XX } C_{\text {max }}, \\
T_{\text {max }}, \mathrm{AUC}_{0-\infty}, \mathrm{t}_{1 / 2} \text {, platelet } \\
\text { aggregation (maximal } \\
\text { and final inhibition), } \\
\text { bleeding time, adverse } \\
\text { events, vital signs, ECG, } \\
\text { clinical chemistry and } \\
\text { hematology, Holter } \\
\text { monitoring, urinalysis, } \\
\text { examination for petechia }\end{array}$ & $\begin{array}{l}\text { Adverse events: no safety or tolerability } \\
\text { issues reported up to } 900 \mathrm{mg} \text {; dose-limiting } \\
\text { gastrointestinal adverse events were } \\
\text { observed (nausea, vomiting, and } \\
\text { abdominal pain) at } 1260 \mathrm{mg}\end{array}$ \\
\hline $\begin{array}{l}\text { Teng }^{28}(2010) \\
(\mathrm{N}=25)\end{array}$ & $\begin{array}{l}0.1,0.3, \mathrm{I}, 3, \mathrm{I} 0 \\
30, \text { and } 100 \mathrm{mg}\end{array}$ & Placebo & $\begin{array}{l}\text { Ticagrelor } \mathrm{C}_{\max }, \mathrm{T}_{\max } \\
\text { AUC }_{0-\infty}, \mathrm{t}_{\mathrm{I} / 2}, \text { platelet }\end{array}$ & $\begin{array}{l}\text { Ticagrelor exhibited dose-proportional } C_{\max } \\
\text { and AUC. Plasma levels were unquantifiable }\end{array}$ \\
\hline
\end{tabular}

(Continued) 
Table I (Continued)

\begin{tabular}{|c|c|c|c|c|}
\hline $\begin{array}{l}\text { Reference } \\
\text { (patients) }\end{array}$ & $\begin{array}{l}\text { Ticagrelor } \\
\text { (dosing) }\end{array}$ & Comparator & End point & Main findings \\
\hline & $\begin{array}{l}\text { escalating one-time } \\
\text { single dose } \times 8 \\
\text { treatment periods } \\
\text { of } 7 \text { - } d \text { duration }\end{array}$ & & $\begin{array}{l}\text { aggregation (maximal } \\
\text { and final inhibition), } \\
\text { bleeding time, adverse } \\
\text { events, vital signs, ECG, } \\
\text { clinical chemistry and } \\
\text { hematology, Holter } \\
\text { monitoring, urinalysis, } \\
\text { examination for petechia }\end{array}$ & 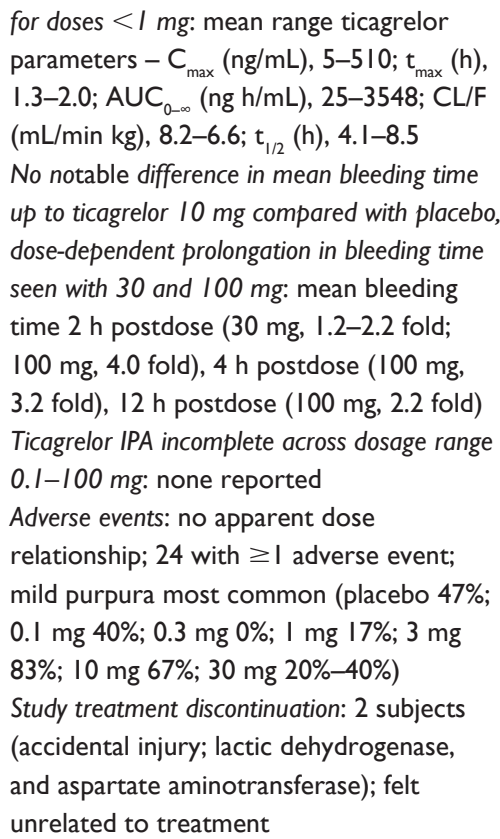 \\
\hline
\end{tabular}

Note: aComplete data not available in publication.

Abbreviations: $C_{\max }$, maximum plasma concentration; $T_{\max }$, time to maximum plasma concentration; $A \cup C_{0-\infty}$, area under the plasma curve concentration; $t_{1 / 2}$, half-life of elimination; ECG, electrocardiogram; $t_{\max }$, time to maximum concentration; CL/F, total plasma oral clearance; IPA, inhibition of platelet aggregation; ADP, adenosine diphosphate; LD, loading dose; $C_{s s}$, concentration steady state; NA, not available.

properties and safety and tolerability in patients with atherosclerosis. A total of 200 patients were randomized to receive ticagrelor $50 \mathrm{mg}(\mathrm{n}=41), 100 \mathrm{mg}(\mathrm{n}=39)$, or $200 \mathrm{mg}(\mathrm{n}=37)$ twice daily, $400 \mathrm{mg}(\mathrm{n}=46)$ once daily, or clopidogrel $75 \mathrm{mg}(\mathrm{n}=37)$ once daily for 28 days in addition to aspirin $75-100 \mathrm{mg}$ once daily.

Inclusion criteria were a confirmed diagnosis of atherosclerotic disease and aspirin therapy at a dose of 75-100 mg once daily for at least 2 weeks or more before randomization. Exclusion criteria included the presence of ACS within 3 months (or percutaneous coronary intervention [PCI] within 4 months) of randomization, increased risk of bleeding, elevated serum creatinine (screening creatinine $>1.2$ times the upper limit of normal), low hemoglobin level ( $\geq 5 \%$ below the lower limit of normal), or platelet count $<125,000 / \mathrm{mm}^{3}$, active liver disease (or indication of liver disease on laboratory screening), and anticoagulant or antiplatelet (other than aspirin) use within 10 or 7 days of randomization.

Measured outcomes included inhibition of ADP-induced platelet aggregation using optical aggregometry of plateletrich plasma (final and maximal extent aggregation in response to $20 \mu \mathrm{M}$ ADP), bleeding time, time dependent-drug plasma concentrations (AUC, $\mathrm{C}_{\max }$, time to maximum concentration $\left[\mathrm{t}_{\max }\right]$, half-life of elimination $\left[\mathrm{t}_{1 / 2}\right]$, total plasma oral clearance $[\mathrm{CL} / \mathrm{F}]$ - all reported as a function of gender or age [ $\leq 65$ years and $>65$ years]), primary tolerability (reported incidence of adverse events, with bleeding complications classified as major or minor), electrocardiogram (ECG), vital sign, and clinical laboratory changes.

Ticagrelor significantly inhibited the ADP-induced platelet aggregation at 2 hours postdose on day 1 and at steady state (days 14 and 28). Platelet inhibition was more rapid with ticagrelor than clopidogrel and was to a greater extent with the doses of $100 \mathrm{mg}$ twice daily, $200 \mathrm{mg}$ twice daily, and $400 \mathrm{mg}$ once daily. Ticagrelor's effect on ADP-induced platelet aggregation was $24 \%-31 \%$ greater than clopidogrel for all 3 doses. Adequate platelet inhibition was maintained throughout the dosing interval with reduced IPA response variability, particularly with ticagrelor dosed twice daily. Platelet inhibition declined 24 hours after the last dose of ticagrelor indicating reversibility. However, IPA levels remained higher in the ticagrelor than clopidogrel group at 24 hours after the last dose, effectively challenging concerns over whether a single missed dose of ticagrelor is clinically significant. 


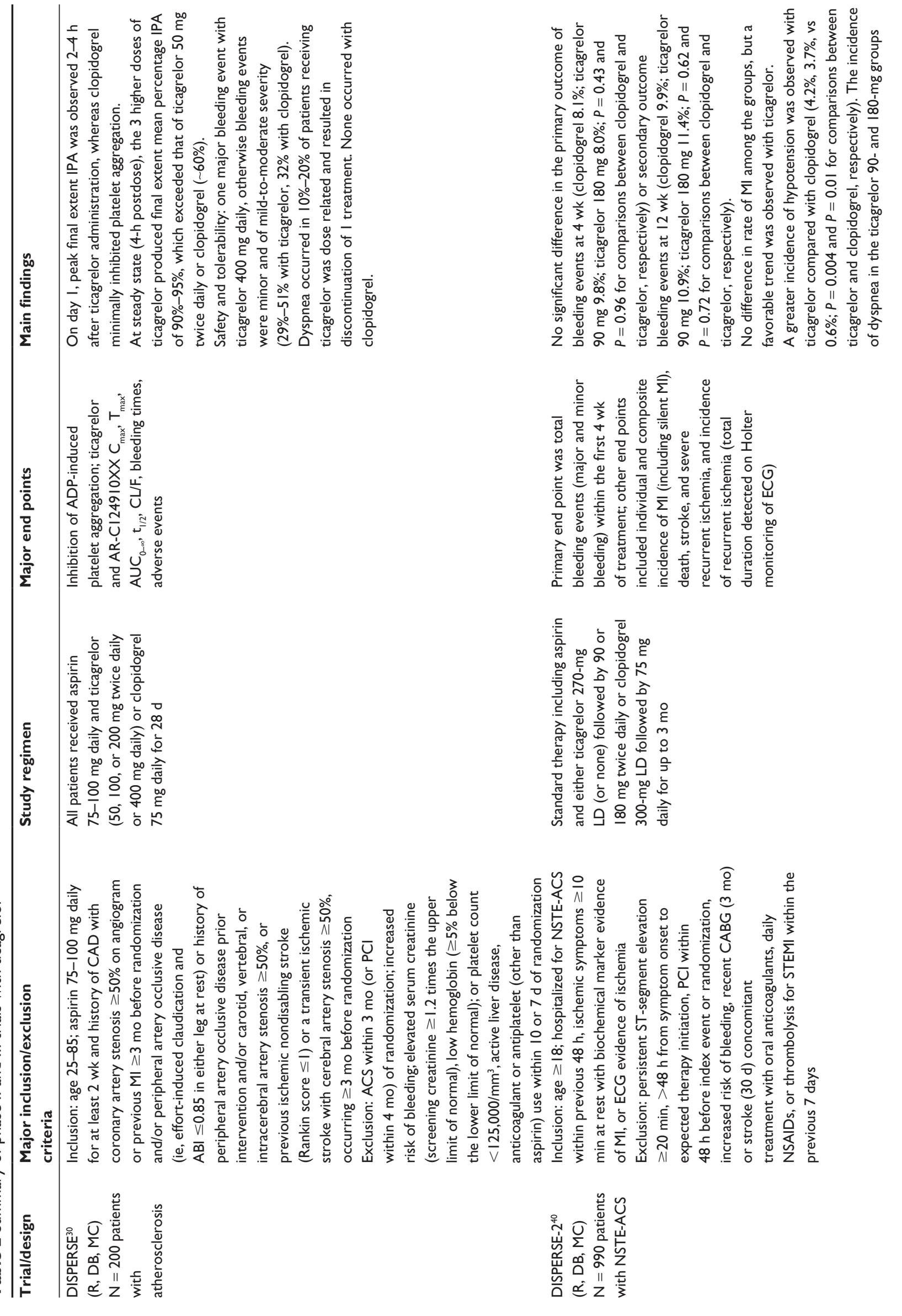




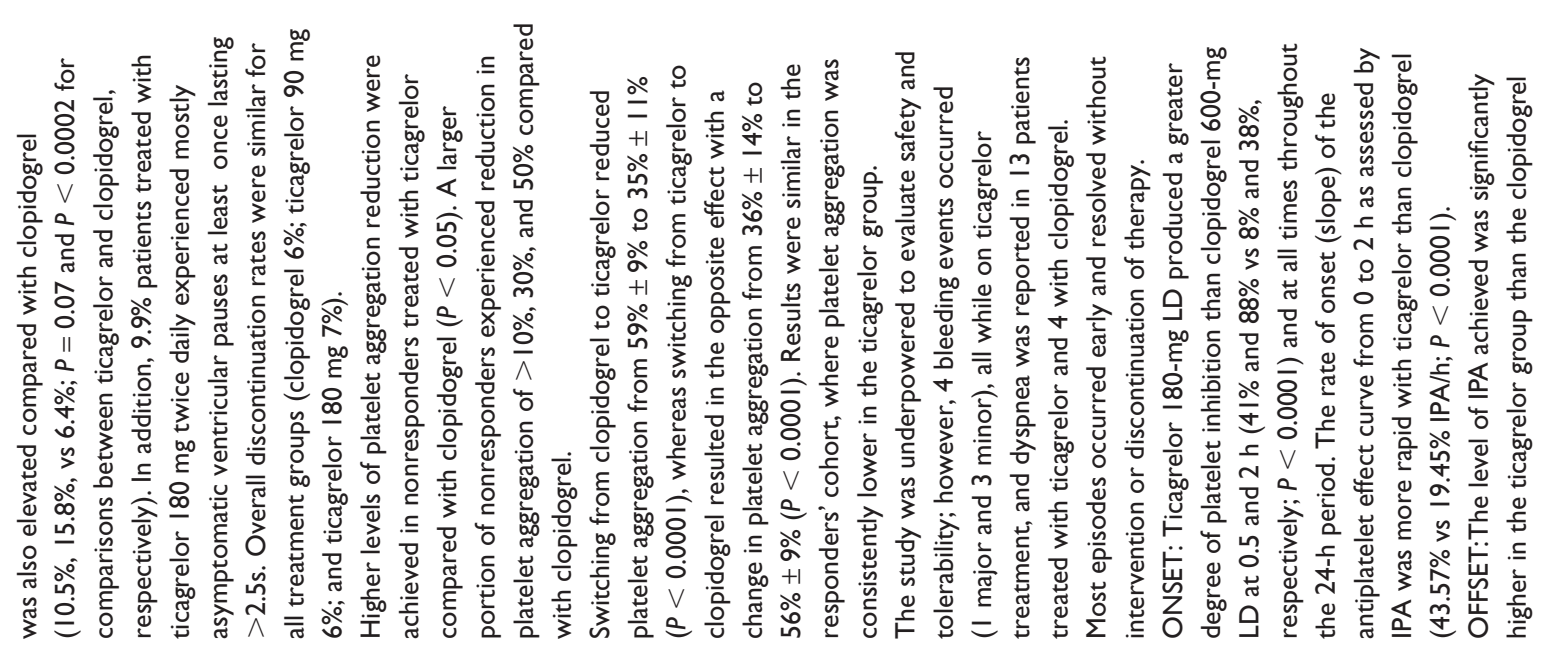

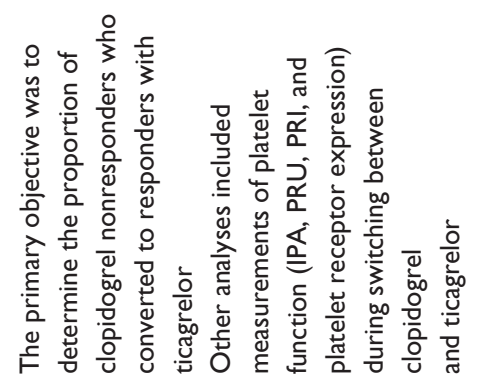
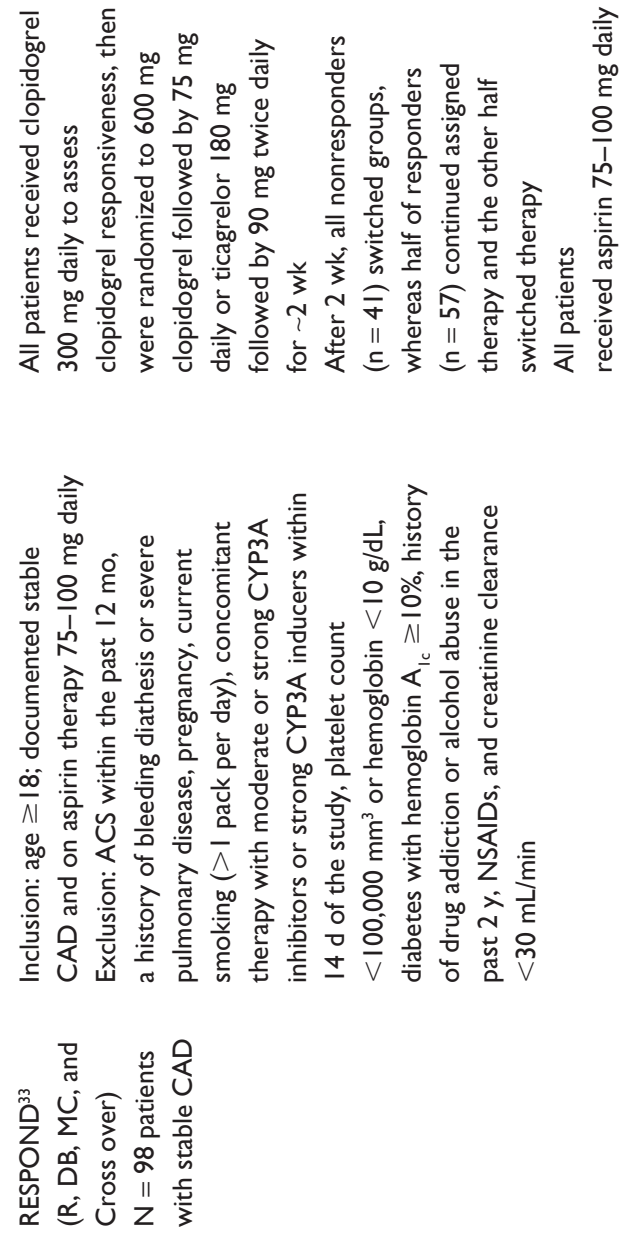

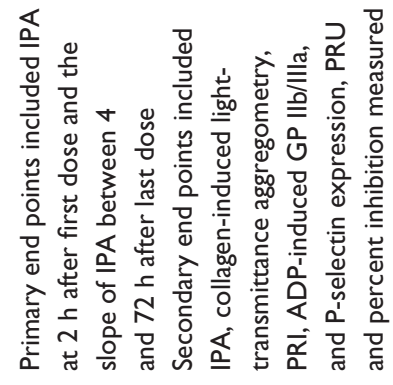

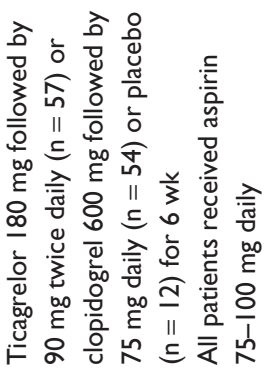

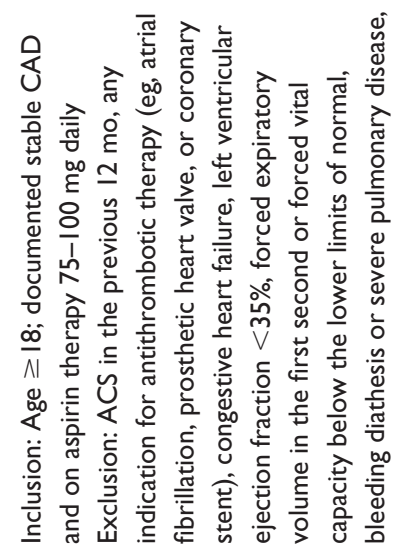

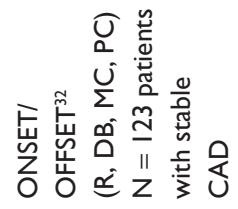




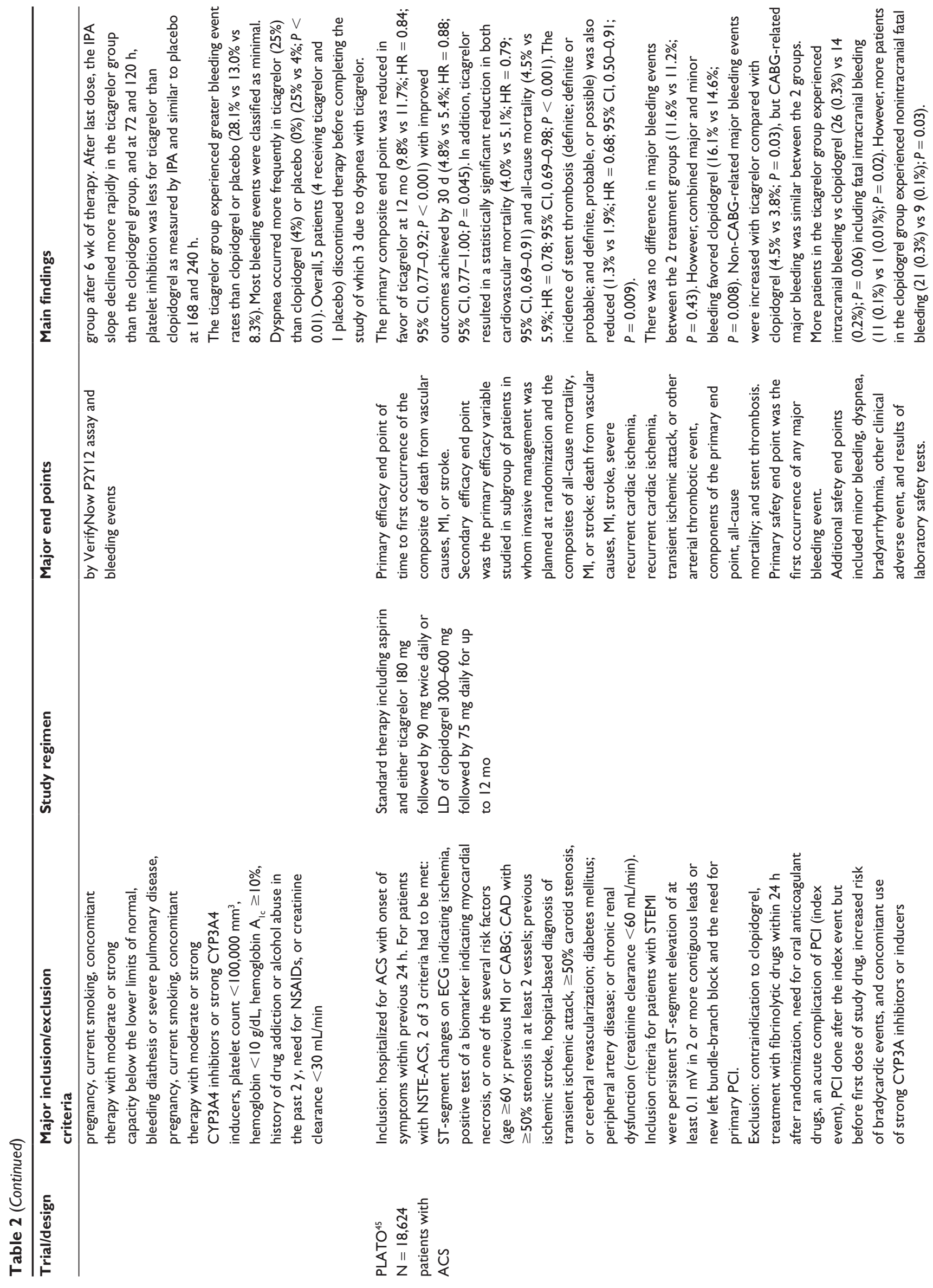




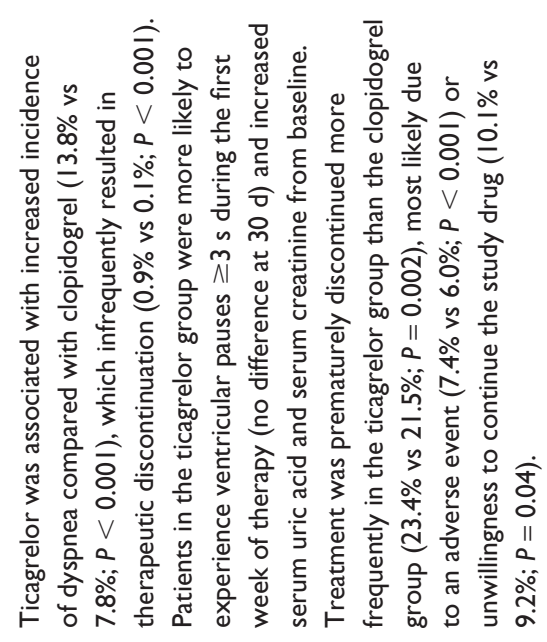

Similar to findings reported in phase I trials, the rate and extent of ticagrelor's maximum IPA (IPA ${ }_{\max }$ ) effect corresponded with time to maximum exposure $\left(\mathrm{T}_{\max }\right)$, with a plateau effect observed for doses $>100 \mathrm{mg}$ twice daily. Ticagrelor pharmacokinetic parameters were not affected by gender or age. These findings suggest ticagrelor $100 \mathrm{mg}$ twice daily as a maintenance dose is as effective as higher doses and superior to clopidogrel at inhibiting platelet aggregation.

In the DISPERSE trial, patients receiving ticagrelor experienced an increased incidence of bleeding, primarily minor, resulting in discontinuation of treatments in 7 patients, of which 4 were receiving the $400 \mathrm{mg}$ once-daily dose. In addition, bleeding times were prolonged in all patients receiving ticagrelor, independent of the dose; this prolongation was to a greater extent than noted with clopidogrel. Other adverse events included dizziness, headache, red blood cells in the urine, and dyspnea.

Dyspnea affected $10 \%-20 \%$ of patients taking ticagrelor and appeared to be dose related. All cases were classified as mild to moderate in severity, with only one resulting in treatment discontinuation and none associated with heart failure or bronchospasm. In contrast to the findings reported in the literature, there were no reports of dyspnea in the clopidogrel treatment arm. Although the mechanism by which ticagrelor results in dyspnea is unknown, a number of theories have been proposed and debated. ${ }^{41-43}$ In addition, all ticagrelor groups exhibited an increase in uric acid levels of 5\%-10\% from baseline. Uric acid levels in patients taking clopidogrel decreased about $10 \%$. One case of ticagrelor discontinuation was due to overdose, and 1 patient discontinued clopidogrel treatment due to polyarthritis. No quality of life or adherence data were reported.

In summary, in the DISPERSE trial, ticagrelor was generally well tolerated and exhibited more rapid, potent, and sustained inhibition of ADP-induced platelet aggregation compared with clopidogrel $75 \mathrm{mg}$ once daily in patients with atherosclerosis taking aspirin. Although the effects of ticagrelor were rapidly reversible, it maintained the high levels of platelet inhibition 24 hours after the last dose of 100, 200, or $400 \mathrm{mg}$ when compared with clopidogrel. Ticagrelor did increase bleeding and dyspnea, possibly in a dose-dependent manner, as well as uric acid levels, compared with clopidogrel. These adverse effects, however, were mostly minor or mild to moderate in nature. Based on the reported findings of the study, the authors concluded that ticagrelor 100 and $200 \mathrm{mg}$ twice daily would be carried forward for future trials due to a favorable balance of safety and efficacy. 


\section{DISPERSE-2 trial}

The DISPERSE-2 trial $^{40}$ was a multicenter, multinational, randomized (1:1:1), double-blinded, dose-confirmation trial to compare safety and efficacy of ticagrelor with clopidogrel in patients with NSTE-ACS. A total of 990 patients treated with aspirin, up to $325 \mathrm{mg}$ initially, then $75-100 \mathrm{mg}$ once daily; standard therapy of ACS, including $\beta$-blocker, statin, and parenteral anticoagulant \pm GP IIb/IIIa inhibitor; and PCI or CABG, as clinically indicated, were randomized to receive ticagrelor $90 \mathrm{mg}$ twice daily, $180 \mathrm{mg}$ twice daily or clopidogrel $300 \mathrm{mg}$ initially (unless already treated with clopidogrel) followed by $75 \mathrm{mg}$ once daily for up to 12 weeks. An additional clopidogrel 300-mg loading dose was allowed for patients scheduled to undergo PCI within 48 hours of randomization. The ticagrelor group was subrandomized to receive a 270-mg loading dose or placebo.

Patients were included if they were hospitalized for NSTE-ACS within 48 hours, experiencing ischemic symptoms $\geq 10$-minute duration at rest, with biochemical marker evidence of myocardial infarction (MI) or ischemia on ECG. Exclusion criteria included persistent ST-segment elevation within $\geq 20$ minutes, $>48$ hours from symptom onset to expected therapy initiation, PCI within 48 hours before index event or randomization, recent CABG (3 months) or stroke (30 days) increased risk of bleeding, concomitant treatment with oral anticoagulants, daily nonsteroidal antiinflammatory drugs (NSAIDs), or thrombolysis for STEMI within the previous 7 days.

Measured outcomes included the following: (1) total bleeding events (major and minor bleeding) within the first 4 weeks of treatment, (2) individual and composite incidence of MI (including silent MI), death, stroke, and severe recurrent ischemia, and (3) incidence of recurrent ischemia (total duration detected on Holter monitoring of ECG).

A total of 984 patients received at least 1 dose of study medication with scheduled treatment for 12 weeks $(50 \%)$, 8 weeks $(25 \%)$, or 4 weeks $(25 \%)$. Median duration of treatment was 56 days. Majority of the patients were men (64\%), and the average age of the overall study population was 63 years. Approximately 24\% of patients had diabetes, 48\% ST-segment depression, and 62\% NSTE-ACS. Most patients received aspirin, heparin, statins, and $\beta$-blockers, and less than one-third received GP IIb/IIIa inhibitors. Over two-thirds of the patients underwent coronary angiography, with $42 \%$ receiving PCI ( $2 \%$ balloon angioplasty and $40 \%$ stenting, of which $48 \%$ were drug eluting) and $9 \%$ CABG.

There was no significant difference in the occurrence of the primary outcome of bleeding events at 4 weeks (clopidogrel

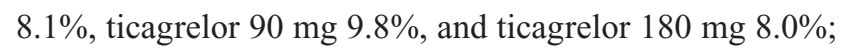
$P=0.43$ and $P=0.96$ for comparisons between clopidogrel and ticagrelor, respectively) or secondary outcome of bleeding events at 12 weeks (clopidogrel 9.9\%, ticagrelor $90 \mathrm{mg}$ $10.9 \%$, and ticagrelor $180 \mathrm{mg} 11.4 \% ; P=0.62$ and $P=0.72$ for comparisons between clopidogrel and ticagrelor, respectively). Two patients suffered fatal bleeds in the ticagrelor $90 \mathrm{mg}$ group although overall rates of major bleeding events (fatal or life-threatening and others) were similar between these groups. Minor bleeding occurred more frequently in the ticagrelor $180 \mathrm{mg}$ group than clopidogrel at both 4

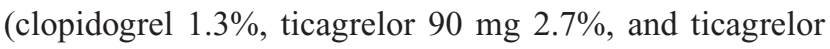
$180 \mathrm{mg} \mathrm{3.8 \%} P=0.18$ and $P=0.0504$ for comparisons between clopidogrel and ticagrelor, respectively) and 12

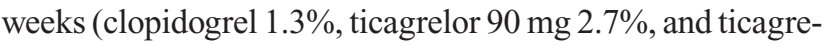
lor $180 \mathrm{mg} 6.1 \% ; P=0.18$ and $P=0.01$ for comparisons between clopidogrel and ticagrelor, respectively).

The majority of all reported bleeding events occurred initially (within the first 4 weeks of treatment). In addition, during the first 48 hours of treatment, bleeding events were numerically more frequent both within the clopidogrel group (clopidogrel 2.8\% major and minor and 2.4\% major bleeds) and in patients who received ticagrelor 270-mg loading dose (3.6\% major and minor and $1.8 \%$ major bleeds ) vs the ticagrelor 90 and $180 \mathrm{mg}$ group who did not receive a loading dose (ticagrelor $90 \mathrm{mg} \mathrm{2.4 \%} \mathrm{major} \mathrm{and} \mathrm{minor} \mathrm{and}$ $1.3 \%$ major bleeds and ticagrelor $180 \mathrm{mg} 1.3 \%$ major [no minor bleeds]).

Bleeding events were often procedure related (clopidogrel

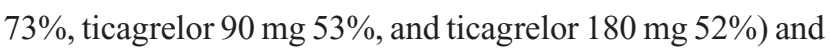
most frequently periprocedural hemorrhage or hematoma. There was minimal difference in reported bleeding events requiring treatment discontinuation (clopidogrel 3 [0.9\%], ticagrelor $90 \mathrm{mg} 8$ [2.4\%], and ticagrelor $180 \mathrm{mg} 5$ [1.5\%] patients) and/or blood transfusions (clopidogrel 22 [6.7\%], ticagrelor $90 \mathrm{mg} 24$ [7.2\%], and ticagrelor $180 \mathrm{mg} 15$ [4.6\%] patients) amongst the clopidogrel or ticagrelor $90 \mathrm{mg}$ and $180 \mathrm{mg}$ groups. For all patients undergoing $\mathrm{CABG}$, incidence of bleeding was numerically greater in patients treated with clopidogrel $(62 \%)$ than ticagrelor (43\%), thus suggesting a theoretical advantage for ticagrelor-treated patients because of rapid reversal of platelet inhibition.

The potential advantage of ticagrelor over clopidogrel in patients undergoing $\mathrm{CABG}$ was further investigated in a post hoc DISPERSE-2 substudy published by Husted et al. ${ }^{44}$ This study reported a nonstatistically significant reduction in $\mathrm{CABG}$-related major bleeding for patients treated with ticagrelor compared with clopidogrel when therapy was 
discontinued within 1-5 days of operation (36\% vs $64 \%$; $P=0.15)$. In addition, major bleeding event rates were similar in patients undergoing $\mathrm{CABG}$ whether treatment was discontinued $<1$ day or $>5$ days before operation. ${ }^{15}$ However, bleeding rates remained constant in clopidogreltreated patients independent of time to $\mathrm{CABG}$, whereas bleeding rates in ticagrelor-treated patients increased when time to $\mathrm{CABG}$ exceeded 5 days compared with $1-5$ days, which suggests a lack of comparability between treatment groups. ${ }^{15}$ In addition, CABG-related major bleeding rates should be viewed as hypothesis generating only, as the DISPERSE-2 trial was not prospectively designed to evaluate these differences.

In the overall DISPERSE-2 trial, rates of MI were similar amongst all treatment groups, with a nonstatistically significant trend toward a lower event rate in the ticagrelor 90 and $180 \mathrm{mg}$ groups compared with clopidogrel at 12 weeks (3.8\%, 2.5\%, vs 5.6\%; $P=0.41$ and $P=0.06$ for comparisons between ticagrelor and clopidogrel, respectively) and a significant reduction in the rate of $\mathrm{MI}$ at 4 weeks with ticagrelor $180 \mathrm{mg}$ ( $1 \%$ vs $3.5 \%$; $P=0.047$ for comparisons between ticagrelor and clopidogrel). The occurrence of MI in the ticagrelor groups was noted to be distributed throughout the study period. The composite of cardiovascular death, MI, or stroke was also similar for all 3 groups at 12 weeks (ticagrelor

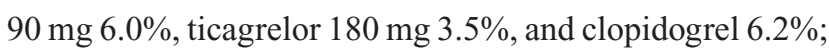
$P=0.9$ and $P=0.12$ for comparisons between ticagrelor and clopidogrel, respectively).

All treatments were generally well tolerated. Patients receiving ticagrelor 90 and $180 \mathrm{mg}$ experienced a greater incidence of hypotension compared with clopidogrel $(4.2 \%$, $3.7 \%$, vs $0.6 \% ; P=0.004$ and $P=0.01$ for comparisons between ticagrelor and clopidogrel, respectively) and the ticagrelor $180 \mathrm{mg}$ group experienced a greater incidence of diarrhea $(7.4 \%$ vs $3.4 \% ; P=0.02)$ and dyspnea $(15.8 \%$ vs $6.4 \% ; P<0.0002)$. The incidence of dyspnea in the ticagrelor 90 and $180 \mathrm{mg}$ groups were also elevated compared with clopidogrel $(10.5 \%, 15.8 \%$, vs $6.4 \% ; P=0.07$ and $P<0.0002$ for comparisons between ticagrelor and clopidogrel, respectively). The increased incidence of dose-related dyspnea with ticagrelor compared with clopidogrel confirms the results of the DISPERSE trial. In combination, both trials suggest dyspnea is a dose-related adverse effect of ticagrelor that occurs occasionally and is of undetermined clinical importance. It should be noted that in the DISPERSE-2 trial, $27 \%$ of patients who reported dyspnea had resolution within 24 hours, 25\% had resolution after 24 hours, and 48\% had persistent symptoms beyond 15 days during treatment. This incidence of persistent dyspnea was $2 \%$ for clopidogrel and $6 \%$ for either of the ticagrelor groups.

Nearly all patients (89.4\%) underwent Holter monitoring in a post hoc analysis. No difference in the rates of ventricular arrhythmias (sustained ventricular tachycardia $>30$ seconds, any episode of nonsustained ventricular tachycardia, or any triplets) were identified; however, patients treated with ticagrelor $180 \mathrm{mg}$ twice daily experienced mostly asymptomatic ventricular pauses lasting $>2.5$ seconds. These occurred at a rate of $9.9 \%$ for at least 1 pause and $4.9 \%$ for $>3$ episodes in the ticagrelor $180 \mathrm{mg}$ group vs $5.5 \%$ and $2.0 \%$ in those receiving $90 \mathrm{mg}$ and $4.3 \%$ and $0.3 \%$ in those receiving clopidogrel. The comparisons were statistically significant only for the ticagrelor $180 \mathrm{mg}$ group vs clopidogrel.

Discontinuation rates were similar for all treatment groups

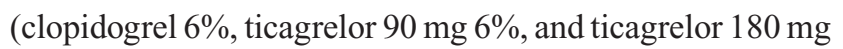
$7 \%$ ). Ticagrelor discontinuation rates due to an adverse event were about $1 \%-4 \%$. Information regarding patient adherence and quality of life measures was not reported.

In conclusion, the DISPERSE-2 trial demonstrated that the addition of ticagrelor 90 or $180 \mathrm{mg}$ twice daily to aspirin, standard ACS therapies, and intervention when necessary in patients with NSTE-ACS was generally as safe as clopidogrel from a combined major and minor bleeding event standpoint. Additionally, most bleeding events occurred within the first 28 days of treatment and were often procedure related. However, the ticagrelor groups did experience a small increase in the incidence of mild bleeding throughout the duration of the study. In addition, patients in the ticagrelor treatment groups did experience an increased incidence of dyspnea compared with clopidogrel, an unexpected finding of mostly asymptomatic ventricular pauses lasting $>2.5$ seconds, hypotension, and mild increases in uric acid levels. It was postulated that these effects may be related to adenosine metabolism. Although the trial was not powered to evaluate the incidence of major adverse cardiovascular events, there appeared to be a dose-related trend in the reduction of MI throughout the study with ticagrelor. In addition, the pharmacokinetic and pharmacodynamic properties observed offered some suggestions that ticagrelor may have an advantage in patients undergoing $\mathrm{CABG}$ or other surgical procedures.

In a substudy of the DISPERSE-2 trial published by Storey et al, ${ }^{31}$ the antiplatelet effects of ticagrelor were assessed in "clopidogrel-pretreated" patients. Regardless of previous clopidogrel exposure, ticagrelor dose dependently inhibited platelet aggregation to a greater degree than clopidogrel 300 and $75 \mathrm{mg}$. IPA with ticagrelor was consistent throughout the duration of the study (eg, 4-hour postdose and day 28). 
Higher ticagrelor dosing also resulted in less interindividual variability. In addition, ticagrelor dose dependently inhibited platelet aggregation to a level not previously achieved in all patients pretreated with clopidogrel, particularly those in the highest tertile of platelet aggregation at baseline. These findings indicate that treatment with ticagrelor resulted in comparable safety and tolerability to clopidogrel while achieving superior IPA independent of the clopidogrel "pretreatment" status.

\section{Phase III trials}

Despite the apparent safety, tolerability, and efficacy signals of ticagrelor, questions remained regarding bleeding risk and the clinical implications of observed adverse events, including asymptomatic ventricular pauses, hypotension, increased uric acid levels, and dyspnea. To further define the clinical role of ticagrelor in the treatment and prevention of cardiovascular disease, three phase III investigations, the PLATelet inhibition and patient Outcomes (PLATO), ONSET/OFFSET, and RESPOND (Response to Ticagrelor in Clopidogrel Nonresponders and Responders and Effect of Switching Therapies) trials, were performed. ${ }^{32,33,45}$ A summary of these phase III trials is included in Table 2.

\section{PLATO trial}

The PLATO trial was a multicenter, multinational, doubleblind, randomized trial to compare the efficacy and safety of ticagrelor and clopidogrel in patients hospitalized with ACS with or without STEMI. ${ }^{45}$

In the PLATO trial, 18,624 patients were randomized within 24 hours of ACS to receive a ticagrelor 180-mg loading dose followed by $90 \mathrm{mg}$ twice daily or clopidogrel 300-mg loading dose (600 mg optional) followed by clopidogrel $75 \mathrm{mg}$ once daily for 6-12 months. If patients were taking clopidogrel for $>5$ days before randomization, the clopidogrel loading dose was avoided. Additional therapies included standard treatments for ACS (aspirin 75-100 mg once daily, $325 \mathrm{mg}$ for 6 months if receiving drug-eluting stent [DES], and 325-mg loading dose for aspirin-naive patients), GP IIb/IIIa inhibitors, and parenteral anticoagulants - oral anticoagulants were not allowed. Provision of an additional ticagrelor $90 \mathrm{mg}$ or clopidogrel 300-mg loading dose for patients undergoing PCI 24 hours after randomization was allowed. For patients undergoing $\mathrm{CABG}$, it was recommended that clopidogrel be continued for 5 days and ticagrelor for 24-72 hours before the procedure.

Patients were eligible if they were hospitalized for ACS, with or without STEMI, with onset of symptoms within the previous 24 hours. For patients with NSTE-ACS, the following 2 of 3 criteria had to be met: ST-segment changes on ECG indicating ischemia, positive test of a biomarker indicating myocardial necrosis, or one of the several risk factors (age $\geq 60$ years; previous $\mathrm{MI}$ or $\mathrm{CABG}$; $\mathrm{CAD}$ with $\geq 50 \%$ stenosis in at least two vessels; previous ischemic stroke, hospitalbased diagnosis of transient ischemic attack, $\geq 50 \%$ carotid stenosis, or cerebral revascularization; diabetes mellitus; peripheral artery disease; or chronic renal dysfunction [creatinine clearance $<60 \mathrm{~mL} / \mathrm{min}]$ ). Inclusion criteria for patients with STEMI included persistent ST-segment elevation of at least $0.1 \mathrm{mV}$ in two or more contiguous leads or new left bundle-branch block and the need for primary PCI.

Exclusion criteria included a contraindication to clopidogrel, treatment with fibrinolytic drugs within 24 hours after randomization, need for oral anticoagulant drugs, an acute complication of PCI (index event), PCI done after the index event but before the first dose of study drug, increased risk of bradycardic events, and concomitant use of strong CYP3A inhibitors or inducers.

Measured outcomes were the primary efficacy end point of time to first occurrence of the composite of death due to vascular causes, MI, or stroke. The secondary efficacy end point was the primary efficacy variable studied in subgroup of patients in whom invasive management was planned at randomization and the composites of all-cause mortality, MI, or stroke; death due to vascular causes, MI, stroke, severe recurrent cardiac ischemia, recurrent cardiac ischemia, transient ischemic attack, or other thrombotic event, components of the primary end point, all-cause mortality; and stent thrombosis. The primary safety end point was the first occurrence of any major bleeding event. Additional safety end points included minor bleeding, dyspnea, bradyarrhythmia, other clinical adverse event, and results of laboratory safety tests.

At time of randomization, the ticagrelor and clopidogrel groups had similar baseline characteristics, nonstudy medications, and procedures. Patient presentation included $43 \%$ NSTE-ACS, 38\% STEMI, and 17\% unstable angina with $61 \%$ of patients undergoing PCI and $\sim 4.5 \%$ CABG during the index hospitalization. Study drug was initiated at a median of 11.3 hours (interquartile range [IQR] 4.8-19.8) after the start of chest pain. Most patients in the clopidogrel group received a loading dose of at least $300 \mathrm{mg}$ (79.1\%) with fewer patients receiving the higher dose of $600 \mathrm{mg}(19.6 \%)$ between time of index event and up to 24 hours after randomization. Additional medical treatment was similar between the two groups. Median duration of study drug exposure was 277 days (IQR 179-365).

The primary composite end point was reduced in favor of ticagrelor at 12 months $(9.8 \%$ vs $11.7 \%$; hazard ratio 
$[\mathrm{HR}]=0.84 ; 95 \%$ confidence interval $[\mathrm{CI}]: 0.77-0.92$; $P<0.001)$ with improved outcomes achieved by 30 days (4.8\% vs $5.4 \%$; HR $=0.88 ; 95 \%$ CI: $0.77-1.00 ; P=0.045)$. The trial results were driven by a reduction in MI and cardiovascular death but not stroke for which the ticagrelor group experienced more hemorrhagic and cryptogenic events. Most importantly, ticagrelor resulted in a statistically significant reduction in both cardiovascular mortality $(4.0 \%$ vs $5.1 \%$; HR $=0.79 ; 95 \%$ CI: $0.69-0.91)$ and all-cause mortality (4.5\% vs $5.9 \%$; HR $=0.78 ; 95 \%$ CI: $0.69-0.98 ; P<0.001)$. PLATO was unique as this was the first trial of platelet P2Y12 inhibitors used in the setting of ACS to demonstrate a clear mortality benefit. The incidence of stent thrombosis (definite; definite or probable; and definite, probable, or possible) was also reduced ( $1.3 \%$ vs $1.9 \%$; $\mathrm{HR}=0.68 ; 95 \%$ CI: $0.50-0.91 ; P=0.009$ ). In addition, in a PLATO substudy analysis of all patients with planned invasive strategy performed by Cannon and Harrington, ${ }^{46}$ the benefit of ticagrelor treatment extended to patients receiving DES. The results of the trial were consistent across ACS subtypes, multiple subgroups, and in patients with planned invasive strategy. ${ }^{46}$ Ticagrelor did not improve outcomes in patients weighing less than their median weight by gender, patients not taking statins, and North American subjects.

There was no difference in major bleeding events between the 2 treatment groups $(11.6 \%$ vs $11.2 \% ; P=0.43)$. However, combined major and minor bleeding favored clopidogrel (16.1\% vs $14.6 \% ; P=0.008)$. Non-CABG-related major bleeding events were increased with ticagrelor compared with clopidogrel $(4.5 \%$ vs $3.8 \% ; P=0.03)$. Unexpectedly, CABG-related major bleeding was similar between the 2 groups, suggesting that the reversible nature of ticagrelor's antiplatelet inhibition may confer some added safety compared with the irreversible thienopyridines. More patients in the ticagrelor group experienced intracranial bleeding compared with clopidogrel (26 [0.3\%] vs $14[0.2 \%] ; P=0.06)$ including fatal intracranial bleeding (11 [0.1\%] vs $1[0.01 \%]$; $P=0.02)$. However, more patients in the clopidogrel group experienced nonintracranial fatal bleeding $(21[0.3 \%]$ vs $9[0.1 \%] ; P=0.03)$. Bleeding rates did not differ across most subgroups, except patients with a body mass index (BMI) $>30 \mathrm{~kg} / \mathrm{m}^{2}$ who experienced major bleeding more frequently with ticagrelor than with clopidogrel. Results were similar when applying thrombolysis in MI (TIMI) bleeding criteria. These findings are consistent with the DISPERSE-2 trial and likely reflect differences in the pharmacokinetic and pharmacodynamic profiles of clopidogrel and ticagrelor as previously discussed.
Although ticagrelor was generally well tolerated, as previously reported, it was associated with increased incidence of dyspnea compared with clopidogrel $(13.8 \%$ vs $7.8 \%$; $P<0.001)$, which infrequently resulted in therapeutic discontinuation $(0.9 \%$ vs $0.1 \% ; P<0.001)$. Patients in the ticagrelor group were also more likely to experience ventricular pauses $\geq 3$ seconds during the first week of therapy (no difference at 30 days) and increased serum uric acid and serum creatinine from baseline, which remained different throughout the study duration, but were no longer different 1 month after study drug discontinuation. These findings confirmed previous reports of adverse events from phase II trials. The PLATO trial was of appropriate size and duration to evaluate the tolerability of ticagrelor compared with clopidogrel. Although the reported adverse events appear manageable, their clinical significance remains uncertain and will require further evaluation with continuous monitoring.

Treatment was prematurely discontinued more frequently in the ticagrelor group than the clopidogrel group $(23.4 \%$ vs $21.5 \% ; P=0.002)$, most likely due to an adverse event (7.4\% vs $6.0 \% ; P<0.001$ ) or unwillingness to continue the study drug $(10.1 \%$ vs $9.2 \% ; P=0.04)$. Information regarding quality of life was not reported. Overall adherence to the study drug was $82.8 \%$.

The PLATO trial demonstrated that in a broad ACS population, ticagrelor added to standard therapy for up to 12 months was more effective than clopidogrel in reducing death due to vascular causes, MI, and stroke while not increasing the risk of major bleeding. The net benefit provided by ticagrelor was instrumental in reducing all-cause mortality, a secondary outcome, which was appropriately tested as part of the hierarchal nature of the analysis. It is conceivable that the primary efficacy outcome may have been overestimated due to the low utilization of higher loading dose of clopidogrel. However, this strategy would likely be at the cost of increased bleeding events.

In addition to the PLATO trial in ACS, two recent clinical trials, the RESPOND study and the ONSET/OFFSET trial, were performed to evaluate ticagrelor and clopidogrel dosing strategies in patients with stable CAD taking daily aspirin. ${ }^{32,33}$

\section{RESPOND study}

The RESPOND study ${ }^{33}$ was a multicenter, multinational, randomized, double-blind, double-dummy, cross over investigation to compare the effects of ticagrelor with clopidogrel in patients with stable CAD taking aspirin who were identified either as nonresponders or responders 
to clopidogrel. Response was assessed using a clopidogrel 300-mg loading dose and defined based on $20 \mu \mathrm{mol} / \mathrm{L}$ ADPinduced platelet aggregation measured before dosing and 6-8 hours after dosing. Clopidogrel nonresponders were defined as those with absolute change in maximum platelet aggregation of $<10 \%$.

A total of 98 patients (41 nonresponders and 57 responders) were randomized to receive a loading dose of ticagrelor $180 \mathrm{mg}$ followed by $90 \mathrm{mg}$ twice daily or clopidogrel $600 \mathrm{mg}$ followed by $75 \mathrm{mg}$ once daily for $14 \pm 2$ days. At the end of first treatment period, patients switched therapies and began second treatment period lasting another $14 \pm 2$ days. Nonresponders switched to the alternative treatment, whereas half of the responders switched and half continued the same regimen. Patients continuing the same regimen did not receive a second loading dose.

Patients aged $\geq 18$ years with documented stable CAD who were taking aspirin 75-100 mg once daily were included. Exclusion criteria of patients included history of ACS within the past 12 months, history of bleeding diathesis or severe pulmonary disease, pregnancy, current smoking $(>1$ pack per day), concomitant therapy with moderate or strong CYP3A inhibitors or strong CYP3A inducers within 14 days of the study, platelet count $<100,000 / \mathrm{mm}^{3}$ or hemoglobin level $<10 \mathrm{~g} / \mathrm{dL}$, diabetes with hemoglobin $\mathrm{A}_{1 \mathrm{c}} \geq 10 \%$, history of drug addiction or alcohol abuse in the past 2 years, nonsteroidal anti-inflammatory drug use, and creatinine clearance $<30 \mathrm{~mL} / \mathrm{min}$.

The primary objective of the study was to determine the proportion of clopidogrel nonresponders who convert to responders with ticagrelor. The effects of study drug on markers of platelet inhibition were evaluated and included: IPA, P2Y12 reaction units (PRU), platelet reactivity index (PRI), and platelet receptor expression. Bleeding events were classified using PLATO criteria, and medication compliance was measured.

Patients were aged $45-85$ years and primarily men. Baseline demographics were similar between the 2 groups, except for a higher proportion of smokers in the responder group. As expected, higher levels of reduction in platelet aggregation were achieved in nonresponders treated with ticagrelor compared with clopidogrel $(P<0.05)$. A larger portion of nonresponders experienced reduction in platelet aggregation of $>10 \%, 30 \%$, and $50 \%$ compared with clopidogrel. Switching from clopidogrel to ticagrelor reduced platelet aggregation from $59 \% \pm 9 \%$ to $35 \% \pm 11 \%(P<0.0001)$, whereas switching from ticagrelor to clopidogrel resulted in the opposite effect with a change in platelet aggregation from $36 \% \pm 14 \%$ to $56 \% \pm 9 \%(P<0.0001)$. Results were similar in the responders' cohort, where platelet aggregation was consistently lower in the ticagrelor group.

In both nonresponders and responders, the IPA ${ }_{\text {max }}$ was achieved more rapidly (1-2 hours) and to a greater extent with ticagrelor than with clopidogrel. Results were similar regardless of the treatment period. The highest levels of IPA occurred after switching from clopidogrel to ticagrelor, whereas switching from ticagrelor to clopidogrel resulted in an initial carryover effect that diminished by day 14 . Finally, platelet reactivity was below cutoff points previously associated with ischemic risk measured by light transmittance aggregometry, VerifyNow ${ }^{\circledR}$ (Accumetrics, San Diego, CA) P2Y12 assay, and VASP phosphorylation (VASP-P) in $98 \%-100 \%$ of patients after ticagrelor treatment compared with 44\%-70\% with clopidogrel.

About $83 \%$ of nonresponders and $95 \%$ of responders completed the study. Reasons for study drug discontinuation in the 2 groups included adverse events ( 5 nonresponders and 1 responder), noncompliance (1 nonresponder), and nontreatment-related reasons (1 nonresponder and 2 responders). Four patients ( 2 clopidogrel responders and 2 clopidogrel nonresponders) experienced five serious adverse events (MI, hypotension, atrial fibrillation, and bradycardia) during or after ticagrelor therapy. One death occurred on day 30 of follow-up and was deemed unrelated to study treatment. Four bleeding events occurred (1 major and 3 minor), all while on ticagrelor treatment. Similar to previous reports, dyspnea was reported in 13 patients treated with ticagrelor and 4 with clopidogrel. Most episodes occurred early and resolved without intervention or discontinuation of therapy.

The RESPOND study provides one of the first accounts of patient adherence with ticagrelor, which was similar between both groups at visit 3 (nonresponders 79\% and responders $79 \%$ ) and visit 5 (nonresponders $89 \%$ and responders $91 \%$ ).

The RESPOND study demonstrated ticagrelor's ability to inhibit platelet aggregation in patients with stable CAD previously identified as clopidogrel nonresponders. Ticagrelor not only produced greater reductions in platelet reactivity in both responders and nonresponders but also resulted in rapid and greater IPA in patients switching from clopidogrel to ticagrelor. The level of platelet aggregation achieved was also more consistently below ischemic cutoff points than clopidogrel as measured by a variety of assays. Based on the superior efficacy, ticagrelor may be considered, pending clinical outcome trials, as a favorable alternative in patients previously reported to be clopidogrel 
nonresponders. The RESPOND study was underpowered to evaluate safety and tolerability. Therefore, a strategy of switching a patient from clopidogrel to ticagrelor should be pursued with caution.

\section{ONSET/OFFSET trial}

The ONSET/OFFSET trial ${ }^{32}$ was a multicenter, multinational, randomized, double-blind, double-dummy, parallel-group study to compare the onset and offset of IPA with ticagrelor using the PLATO trial's loading dose (180 mg) with a high loading dose $(600 \mathrm{mg})$ of clopidogrel in patients with stable CAD taking aspirin.

A total of 123 patients were randomized to receive ticagrelor 180-mg loading dose followed by $90 \mathrm{mg}$ twice daily or clopidogrel 600-mg loading dose followed by $75 \mathrm{mg}$ once daily or placebo in addition to aspirin 75-100 mg for 6 weeks followed by a 10-day offset period.

Patients $\geq 18$ years of age with documented CAD who were receiving aspirin therapy were included. Exclusion criteria included history of ACS in the previous 12 months, any indication for antithrombotic therapy (eg, atrial fibrillation, prosthetic heart valve, or coronary stent), congestive heart failure, left ventricular ejection fraction $<35 \%$, forced expiratory volume (FEV) in the first second or forced vital capacity (FVC) below the lower limits of normal, bleeding diathesis or severe pulmonary disease, pregnancy, current smoking, concomitant therapy with moderate or strong CYP3A4 inhibitors or strong CYP3A4 inducers, platelet count $<100,000 / \mathrm{mm}^{3}$, hemoglobin $<10 \mathrm{~g} / \mathrm{dL}$, hemoglobin $A_{1 c} \geq 10 \%$, history of drug addiction or alcohol abuse in the past 2 years, need for nonsteroidal anti-inflammatory drug, or creatinine clearance $<30 \mathrm{~mL} / \mathrm{min}$.

Primary end points of the ONSET study included IPA at 2 hours after first dose and the slope of IPA between 4 and 72 hours after last dose. Secondary end points included a number of pharmacodynamic measures of platelet activity, including IPA, collagen-induced light transmittance aggregometry, PRI, ADP-induced GP IIb/IIIa, and P-selectin expression, PRU and percent inhibition measured by VerifyNow P2Y12 assay; bleeding events as defined by PLATO criteria; and medication compliance.

A total of 57 patients were randomized to ticagrelor treatment, 54 to clopidogrel, and 12 to placebo $(52,51$, and 11 patients in each group, respectively, completed the study). The patients were primarily white and aged $41-83$ years. Baseline demographics were similar in all treatment groups (72\% family history of CAD, 75\% hypertension, 96\% hyperlipidemia, and $45 \%$ prior $\mathrm{MI})$.

\section{ONSET}

A ticagrelor 180-mg loading dose produced a greater degree of platelet inhibition than clopidogrel 600-mg loading dose at 0.5 and 2 hours $(41 \%$ and $88 \%$ vs $8 \%$ and $38 \%$, respectively; $P<0.0001$ ) and at all times throughout the 24-hour period. Additionally, the rate of onset (slope) of the antiplatelet effect curve from 0 to 2 hours as assessed by IPA was more rapid with ticagrelor than clopidogrel (43.57\% vs $19.45 \%$ IPA/h; $P<0.0001)$. In fact, within 1 hour of administration of a ticagrelor loading dose the IPA achieved was greater than the IPA ${ }_{\text {max }}$ eventually produced ( 7.8 hours) by the loading dose of clopidogrel. Ticagrelor produced an IPA $_{\max }$ of $93 \%$ at 2 hours, which resulted in a larger portion of patients achieving $>50 \%$ IPA $(98 \%$ vs $31 \% ; P<0.0001)$ and $>70 \%$ IPA $(90 \%$ vs $16 \% ; P<0.0001)$ when compared with clopidogrel.

\section{OFFSET}

The level of IPA achieved was significantly higher in the ticagrelor group than the clopidogrel group indicating sustained and consistent platelet inhibition after 6 weeks of therapy. After last dose, the IPA slope declined more rapidly in the ticagrelor group than the clopidogrel group. Importantly, at 24-48 hours, the level of IPA for ticagrelor and clopidogrel was not significantly different. However, by 72 and 120 hours platelet inhibition was less for ticagrelor than clopidogrel as measured by IPA and similar to placebo by 168 and 240 hours. The rate of offset (slope of the antiplatelet effect curve) from 4 to 72 hours after last dose was more rapid in the ticagrelor group (-1.04\% vs $-0.48 \%$ IPA/h; $P<0.0001)$, resulting in a quicker reduction of IPA from $30 \%$ to $10 \%$ (53.30 hours vs 116.20 hours) and time to 10\% IPA (109.19 hours vs 195.66 hours). Overall, IPA levels for ticagrelor and clopidogrel after last dose were similar at days 3 and 5 and days 5 and 7, respectively.

The ticagrelor group experienced greater bleeding event rates than clopidogrel or placebo $(28.1 \%, 13.0 \%$, vs $8.3 \%$, respectively). Most bleeding events were classified as minimal. Dyspnea occurred more frequently in ticagrelor (25\%) than clopidogrel $(4 \%)$ or placebo $(0 \%)(25 \%$ vs $4 \% ; P<0.01)$. Overall, 5 patients ( 4 receiving ticagrelor and 1 placebo) discontinued therapy before completing the study of which 3 were due to dyspnea with ticagrelor. Throughout the trial, compliance rates were acceptable at $>95 \%$.

The results of the ONSET/OFFSET trial demonstrate that ticagrelor loading dose produces a more rapid and potent level of platelet inhibition compared with a high loading dose of clopidogrel in patients with stable CAD. The level of platelet inhibition achieved with ticagrelor was greater than 
clopidogrel and sustained over a period of 6 weeks. In addition, ticagrelor's reversible inhibition of platelets suggests a more rapid theoretical reversal of bleeding compared with clopidogrel after discontinuation of therapy at steady state, although the IPA levels did not become statistically significantly different until 72 hours. This was the first study to compare pharmacokinetic and pharmacodynamic effects of ticagrelor and clopidogrel immediately after dosing and using a strategy of the highest recommended dose for clopidogrel loading. Similar to the RESPOND trial and previous phase II studies, the ONSET/OFFSET trial was of short duration and not powered to evaluate the safety and tolerance of ticagrelor or the abrupt discontinuation of antiplatelet therapy in patients with stable CAD.

\section{Patient-focused perspectives}

To our knowledge, quality of life and satisfaction information in patients taking ticagrelor have not been published in the literature. In the PLATO substudy trial design, it was noted by James et $\mathrm{al}^{47}$ that quality of life was measured at time of hospital discharge. This information was not discussed by Cannon and Harrington. ${ }^{46}$ Medication adherence was acceptable in most clinical trials as discussed previously in this article. To our knowledge, there are no ongoing trials specifically designed to address these issues.

\section{Dosing and administration}

A range of ticagrelor dosing strategies has been investigated in phase I, II, and III clinical trials. Dosing will most likely be based on the regimen utilized in the PLATO trial. In patients with ACS undergoing PCI, the timing of ticagrelor dosing is important. Prior to PCI, a loading dose of $180 \mathrm{mg}$ of ticagrelor should be administered 1-2 hours before the procedure then followed by $90 \mathrm{mg}$ twice daily. In patients who have already received a loading dose $>24$ hours prior to PCI, an additional 90-mg loading dose may be given. Prior to $\mathrm{CABG}$, ticagrelor should be discontinued for 72 hours and possibly longer based on the results of the ONSET/OFFSET trial. The recommended duration of therapy post-ACS will likely be up to 12 months.

Dosage reduction strategies were not evaluated in the phase III clinical trials. In PLATO trial, patients with a BMI $>30 \mathrm{~kg} / \mathrm{m}^{2}$ experienced a greater incidence of major bleeding events. Also, ticagrelor was not studied in patients with an estimated creatinine clearance $<30 \mathrm{~mL} /$ min. Ticagrelor should be used cautiously in obese patients with ACS and avoided in patients with significant renal dysfunction. Ticagrelor is significantly metabolized by the hepatic CYP3A4 and should be used with caution in patients with moderate or severe hepatic dysfunction.

Concomitant use of ticagrelor with moderate and strong CYP3A4 inhibitors, strong CYP3A4 inducers, and oral anticoagulants was not studied in clinical trials. Ticagrelor should not be administered in patients taking these therapies until additional information is available. In the PLATO trial, patients who were receiving therapy with strong CYP3A4 inhibitors, such as ketoconazole, itraconazole, voriconazole, telithromycin, clarithromycin, nefazodone, ritonavir, saquinavir, nelfinavir, indinavir, atazanavir, and grapefruit juice $>1 \mathrm{~L} / \mathrm{d}, \mathrm{CYP} 3 \mathrm{~A}$ substrates with narrow therapeutic indices (cyclosporine and quinidine), or strong CYP3A inducers (rifampin or rifampicin, phenytoin, and carbamazepine) were excluded. Aspirin, parenteral anticoagulants, and GP IIb/IIIa inhibitors were administered concomitantly with ticagrelor in patients with ACS. Dosing recommendations for standard therapies should be followed in accordance with established guidelines.

In ACS patients who are determined to be clopidogrel nonresponders, a strategy of replacing the clopidogrel with ticagrelor 180-mg loading dose followed by $90 \mathrm{mg}$ twice daily after 24 hours appears attractive but needs to be evaluated in a properly powered clinical outcome trial. Replacement with ticagrelor may initially result in greater platelet inhibition than previously achieved and, thus, close monitoring and patient education are warranted.

Due to the twice daily dose administration requirements of ticagrelor medication, noncompliance has been raised as a concern. Based on the sustained antiplatelet effect of ticagrelor 24 hours after discontinuation of therapy, it is unlikely that a patient will experience a rebound effect. However, patients should be continually educated regarding the safety concerns and risks associated with medication noncompliance.

\section{Safety and tolerability}

Ticagrelor has been studied in a phase III clinical outcome trial of ACS. ${ }^{45}$ However, its efficacy and safety in other clinical situations (such as stable angina, elective PCI, and stroke) have not been evaluated in any clinical outcome trials. Therefore, its use in these situations cannot be recommended at this time. In addition, certain patient groups were excluded from the PLATO trial and, thus, should not be considered for treatment with ticagrelor without further study. This includes patients receiving fibrinolytic treatment within the previous 24 hours, a need for oral anticoagulation, an increased risk for bradycardia, moderate to severe liver disease, need for dialysis, active bleeding or bleeding history, major operation within 30 days, pregnancy or lactation, clinically important 
anemia or thrombocytopenia, and concomitant treatment with a strong CYP3A inhibitor or inducer. It should be used cautiously in patient receiving moderate CYP3A inhibitors or inducers.

The definition of bleeding in PLATO trial was more inclusive than either the TIMI or the Clopidogrel in Unstable angina to prevent Recurrent Events (CURE) protocols and was felt to more appropriately assess the bleeding risk of long-term antiplatelet therapy. ${ }^{47}$ Bleeding events were the primary safety end point, and major bleeding was defined as life-threatening, if it met the following criteria: fatal, intracranial, or pericardial (with cardiac tamponade, hypovolemia, and shock), or severe hypotension requiring resuscitation with vasopressors or operation (Table 3 ). In addition, it had to be associated with a decrease in the level of hemoglobin $>5.0 \mathrm{~g} / \mathrm{dL}$, or a transfusion requirement of $>4 \mathrm{U}$ of whole blood or packed red blood cells. Other bleeding was considered major if it was associated with significant disability (such as intraocular bleeding with permanent vision loss) and accompanied by a 3.0-5.0 g/dL decrease in hemoglobin level or transfusion of 2-3 U of blood. Minor bleeding was defined as any hemorrhage requiring medical intervention, and a minimal bleeding was any bleed that did not require treatment. There was no overall difference in protocol defined or TIMI major bleeding between clopidogrel and ticagrelor. Ticagrelor was associated with a higher rate of non-CABG-related major bleeding and a greater number of fatal intracranial hemorrhages. There were fewer episodes of CABG-related major bleeds and fatal (nonintracranial) bleeding with ticagrelor. Of all the subgroups, there was no significant difference in bleeding risk except for heterogeneity with BMI, with an interaction $P$ value of 0.05 . Patients with a BMI $\geq 30 \mathrm{~kg} / \mathrm{m}^{2}$ had less major bleeding with clopidogrel.

Although ticagrelor is a more potent antiplatelet agent than clopidogrel, no net increase in major bleeding was found in animal studies. It has been proposed that there is a wider separation of the anithrombotic effects from the bleeding risk with ticagrelor compared with thienopyridines. ${ }^{22}$ In rat and dog models, ticagrelor was able to achieve antithrombotic effects that surpassed thienopyridines without an equivalent elevation of the bleeding time. ${ }^{48}$

Typically, cardiovascular surgeons prefer to wait 5-7 days after withdrawal of a thienopyridine prior to CABG. The reversible inhibition of $\mathrm{P} 2 \mathrm{Y} 12$ platelet receptors of ticagrelor has resulted in speculation that it may be a safer alternative for patients requiring earlier operations compared with thienopyridines. ${ }^{23}$ This advantage has not been realized, as there was no difference to ticagrelor over clopidogrel in terms of risk of major CABG-related bleeding in PLATO trial. In DISPERSE-2 study, there were numerically fewer major bleeds in patients undergoing CABG between 1 and 5 days after discontinuing these drugs, although the difference did not appear to be statistically significant. ${ }^{43}$ The primary end point for offset in the ONSET/OFFSET trial was the slope of the antiplatelet effect curve. ${ }^{32}$ This was assessed using $20 \mu \mathrm{mol} / \mathrm{L}$ of ADP by light transmittance aggregometry (measured by IPA) and revealed a more rapid offset for ticagrelor compared with clopidogrel. However, it is also apparent that platelet inhibition (IPA) after study drug was discontinued did not become statistically significant until 72 hours, and platelet inhibition assessed by VerifyNow and VASP-P never showed a statistical difference between ticagrelor and clopidogrel in the hours and days after study drug discontinuation. Thus, the hope that ticagrelor offers a significant advantage over thienopyridines in the first 3 days after discontinuation has not been supported by the available data.

Ventricular pauses were seen more commonly with ticagrelor in clinical trials. A post hoc analysis of DISPERSE-2 demonstrated a greater number of ventricular pauses in the ticagrelor group, which usually remained asymptomatic. Most pauses were reported to be due to sinus block or sinus exit block, although there were 4 patients who experienced complete heart block. In PLATO trial, Holter monitoring was performed during the initial week of therapy

Table 3 Adverse events in PLATO bleeding

\begin{tabular}{|c|c|c|c|c|}
\hline Event & Ticagrelor & Clopidogrel & Hazard ratio & $P$ value \\
\hline Major bleeding & $961 / 9235$ (II.6) & $929 / 9186(11.2)$ & $1.04(0.95-I .13)$ & 0.43 \\
\hline Life-threatening bleed & $491 / 9235$ (5.8) & $480 / 9186(5.8)$ & $1.03(0.90-1.16)$ & 0.70 \\
\hline Fatal bleed & $20 / 9235(0.3)$ & $23 / 9186(0.3)$ & $0.87(0.48-1.59)$ & 0.66 \\
\hline Intracranial bleed & $26 / 9235(0.3)$ & $|4 / 9| 86$ (0.2) & I.87 (0.98-3.58) & 0.06 \\
\hline Fatal intracranial bleed & II/9235 (0.1) & $1 / 9186(0.01)$ & - & 0.02 \\
\hline Non-CABG-related bleed & $362 / 9235(4.5)$ & $306 / 9186(3.8)$ & $1.19(1.02-1.38)$ & 0.03 \\
\hline CABG-related bleed & $619 / 9235(7.4)$ & $654 / 9186(7.9)$ & $0.95(0.85-1.06)$ & 0.32 \\
\hline Major or minor bleeding & $1339 / 9235$ (16.1) & $1215 / 9186(14.6)$ & I.II (I.03-I.20) & 0.008 \\
\hline
\end{tabular}


Table 4 Nonbleeding-related adverse events in PLATO trial

\begin{tabular}{|c|c|c|c|c|}
\hline Event & Ticagrelor & Clopidogrel & Hazard ratio & $P$ value \\
\hline Dyspnea, any & I270/9235 (13.8) & $721 / 9186(7.8)$ & I.84 (1.68-2.02) & $<0.001$ \\
\hline Dyspnea requiring discontinuation & 79/9235 (0.9) & $13 / 9 \mid 86(0.1)$ & $6.12(3.4 I-11.01)$ & $<0.001$ \\
\hline \multicolumn{5}{|l|}{ of study drug } \\
\hline Bradycardia & $409 / 9235(4.4)$ & $372 / 9186(4.0)$ & - & 0.21 \\
\hline Syncope & $100 / 9235(1.1)$ & $76 / 9186(0.8)$ & - & 0.08 \\
\hline Heart block & $67 / 9235(0.7)$ & $66 / 9186(0.7)$ & - & 1.00 \\
\hline $\begin{array}{l}\text { Ventricular pauses (first week of study) } \geq 3 \mathrm{~s} \\
\text { on Holter monitoring }\end{array}$ & $84 / 1451(5.8)$ & $5 I / 14 I 5(3.6)$ & - & 0.01 \\
\hline $\begin{array}{l}\text { Ventricular pauses (first week of study) } \geq 5 \mathrm{~s} \\
\text { on Holter monitoring }\end{array}$ & $29 / 1451(2.0)$ & $17 / 1415(1.2)$ & - & 0.10 \\
\hline $\begin{array}{l}\text { Ventricular pauses (at } 30 \mathrm{~d} \text { ) } \geq 3 \mathrm{~s} \\
\text { on Holter monitoring }\end{array}$ & $2 \mathrm{I} / 985(2.1)$ & $17 / 1006(1.7)$ & - & 0.52 \\
\hline $\begin{array}{l}\text { Ventricular pauses (at } 30 \mathrm{~d} \text { ) } \geq 5 \mathrm{~s} \\
\text { on Holter monitoring }\end{array}$ & $8 / 985(0.8)$ & $6 / 1006(0.6)$ & - & 0.60 \\
\hline
\end{tabular}

and then was repeated at 30 days in a total of 1,991 patients (Table 4). Although a greater number of pauses lasting 3 seconds or longer were seen in the ticagrelor group, there was no significant difference between the two groups. The pauses were rarely symptomatic, with no difference reported in the incidence of syncope, complete heart block, or pacemaker insertion. About $90 \%$ of patients in both groups were given $\beta$-blockers either during hospitalization or at discharge. However, it is also important to remember that patients at an increased risk for bradycardia were excluded from the PLATO trial.

A prespecified subgroup analysis of the ONSET/ OFFSET trial evaluated cardiac and pulmonary function testing in 123 patients with stable CAD, who were given ticagrelor, clopidogrel, and placebo. Dyspnea was reported in $38.6 \%$ of patients receiving ticagrelor compared with $9.3 \%$ of those receiving clopidogrel and $8.3 \%$ on placebo. Most patients (17 of 22) had symptoms develop within 1 week of therapy with ticagrelor, and the dyspnea was usually described as mild. There were 3 (out of 57) patients who discontinued ticagrelor because of dyspnea, and there were 3 patients in the ticagrelor group whose dyspnea was persistent after ticagrelor withdrawal at the end of the study. However, it is important to note that the patients with a FEV in 1 second or a FVC below the lower limit of normal for age were excluded from this trial. No difference in any cardiopulmonary testing, including blood pressure, heart rate, ECG, echocardiogram, left ventricular ejection fraction, N-terminal probrain natriuretic peptide, oxygen saturation, or pulmonary function testing, was apparent among ticagrelor, clopidogrel, and placebo before, during, or after the 6 -week study. ${ }^{49}$
The use of ticagrelor in the setting of pulmonary disease has not been prospectively studied. There was a $13.8 \%$ incidence of dyspnea in the PLATO trial in those receiving ticagrelor, although this adverse event resulted in $<1 \%$ discontinuation of the drug. From the DISPERSE-2 study, it appears that dyspnea is a dose-related side effect of ticagrelor; however, it has not been associated with vascular congestion, congestive heart failure, or bronchospasm. The etiology of the dyspnea remains unknown, although there is speculation that it may be the result of altered adenosine metabolism. ${ }^{50}$

Other notable adverse events with ticagrelor in PLATO trial included an increase in the level of serum uric acid and serum creatinine. Both of these levels returned to baseline at the end of the trial after the study drug was discontinued.

Because ticagrelor was given on a twice-daily dosing schedule, there has been a concern about patient compliance. If a dose is missed, the patient may be at increased risk for stent thrombosis. Upon inspection of the data from the ONSET/OFFSET trial, it appears that patients who miss a single dose of ticagrelor will have a level of platelet inhibition comparable with clopidogrel. No statistical difference in platelet inhibition, as measured by IPA, was noted until both drugs had been stopped for 72 hours.

\section{Conclusion}

The mortality benefit of ticagrelor is unique among contemporary ACS trials of antiplatelet agents and may be the result of a wider separation of antithrombotic effects from the bleeding risk when compared with the currently available thienopyridines. ${ }^{22}$ Another possible explanation for 
mortality benefit could be the reported "off-target" effects; the P2Y12 receptor exists not only on the platelet surface but also in vascular smooth muscle. It is felt that the short half-life of the active metabolite of clopidogrel does not allow the systemic interaction with the nonplatelet P2Y12 receptor, whereas ticagrelor is systemically available. This could conceivably have an effect on the vascular tone and risk of thrombosis in tissues by inhibiting the ADP receptor locally. Other explanations for the survival benefit seen in the PLATO trial include a modulation of the metabolism of adenosine or a reduction in the erythrocyte uptake of adenosine. ${ }^{51}$ Of note, in the PLATO trial, all-cause mortality and death due to vascular disease were secondary outcomes, and although the trial was not powered to assess these secondary outcomes, appropriate hierarchical statistical methods allow this analysis to be considered a clinically relevant finding. ${ }^{52}$

When inspecting the Kaplan-Meier efficacy outcome curves of PLATO, it is apparent that the advantage of ticagrelor is not immediate and it begins to manifest by 30 days and persists over time as the curves continue to separate. Thus, the criticism about an inadequate loading dose of clopidogrel ${ }^{53}$ becomes less relevant in the longer term, particularly as comparison of the outcomes during the initial course of therapy do not appear to differ. This contrasts with the results of the TRITON (Trial to Assess Improvement in Therapeutic Outcomes by Optimizing Platelet Inhibition with Prasugrel-Thrombolysis in Myocardial Infarction [TRITON-TIMI 38]) study, ${ }^{18,19}$ where distinction in these curves between prasugrel and clopidogrel was seen within the first few days of therapy.

Despite the advantages observed with ticagrelor, additional questions do remain. There were 33 subgroups that were prespecified and evaluated in PLATO trial and 3 revealed significant heterogeneity. A lack of a clear advantage of ticagrelor over clopidogrel in North America was found which may be spurious ${ }^{54}$ due to the relatively small number of patients enrolled from this region ( $<10 \%$ of total). In FDA briefing documents, the drug sponsor suggested that the discrepancy between North America and other sites in the PLATO trial could be the result of the higher aspirin dosage (the dose used in America was typically $325 \mathrm{mg}$ vs 75 or $100 \mathrm{mg}$ outside of the United States). ${ }^{55}$ Unfortunately the FDA reviewers had many issues with this analysis, and it was concluded that this disparity may not account for the findings. Men who weighed $<80 \mathrm{~kg}$ and women weighed $<71 \mathrm{~kg}$ were found not to benefit from ticagrelor compared with clopidogrel. In addition, patients who were not taking lipid-lowering drugs on enrollment in the study did not seem to benefit. The presence of heterogeneity when comparing a large number of subgroups needs to be interpreted with caution; ${ }^{56}$ however, further studies are warranted. Additionally, it is unfortunate that no long-term follow-up after 12 months, as in a registry, was attempted. This must be considered an opportunity lost.

In conclusion, ticagrelor represents advancement over currently available oral antiplatelet agents. Its advantages include rapid onset of action, a lack of need for metabolic conversion, an acceptable safety profile, and documented effectiveness in reducing cardiovascular events and mortality in the setting of ACS.

\section{Disclosure}

The authors report no conflicts of interest in this work.

\section{References}

1. World Health Organization. World Health Organization Fact sheet No 317. Available from: http://www.who.int/mediacentre/factsheets/ fs317/en/print.html. Updated September 2009. Accessed June 6, 2010.

2. Brown MS, Goldstein JL. Heart attacks: gone with the century? Science. 1996;272(5262):629.

3. Greenland P, Lloyd-Jones D. Time to end the mixed- and often incorrect-messages about prevention and treatment of atherosclerotic cardiovascular disease. J Am Coll Cardiol. 2007;50:2133-2135.

4. Dahlof B. Cardiovascular disease risk factors: epidemiology and risk assessment. Am J Cardiol. 2010;105:3A-9A.

5. Lloyd-Jones D, Adams J, Brown TM, et al. Heart disease and stroke statistics - 2010 update: a report from the American Heart Association. Circulation. 2010;121:e46-e215.

6. Yeh RW, Sidney S, Chandra M, Sorel M, Selby JV, Go AS. Population trends in the incidence and outcomes of acute myocardial infarction. N Engl J Med. 2010;362:2155-2165.

7. Raju NC, Eikelboom JW, Hirsh J. Platelet ADP-receptor antagonists for cardiovascular disease: past, present, and future. Nat Clin Prac Cardiovas Med. 2008;5:766-780.

8. Narula J, Finn AV, DeMaria AN. Picking plaques that pop. J Am Coll Cardiol. 2005;45:1970-1973.

9. Hillis LD, Lange RA. Optimal management of acute coronary syndromes. N Engl J Med. 2009;360:2237-2240.

10. Chew DP, Bhatt DL, Sapp S, Topol EJ. Increased mortality with oral platelet glycoprotein IIb/IIIa antagonists: a meta-analysis of phase III multicenter randomized trials. Circulation. 2001;103:201-206.

11. Baigent C, Collins R, Appleby P, Parish S, Sleight P, Peto R. ISIS-2: 10 year survival among patients with suspected acute myocardial infarction in randomized comparison of intravenous streptokinase, oral aspirin, both, or neither. The ISIS-2 (Second International Study of Infarct Survival) Collaborative Group. BMJ. 1998;316:1337-1343.

12. Peters RJ, Mehta SR, Fox KA, et al. Effects of aspirin dose when used alone or in combination with clopidogrel in patients with acute coronary syndromes: observations from the Clopidogrel in Unstable angina to prevent Recurrent Events (CURE) study. Circulation. 2003; 108:1682-1687.

13. Anderson JL, Adams CD, Antman EM, et al. ACC/AHA 2007 guidelines for the management of patients with unstable angina/non ST-elevation myocardial infarction: a report of the American College of Cardiology/ American Heart Association task force on practice guidelines (Writing committee to revise the 2002 guidelines for the management of patients with unstable angina/non ST-elevation myocardial infarction). Circulation. 2007;116:e148-e304. 
14. Bertrand ME, Rupprecht H, Urban P, Gershlick AH; CLASSICS Investigators. Double-blind study of the safety of clopidogrel with and without a loading dose in combination with aspirin compared with ticlopidine in combination with aspirin after coronary stenting: the Clopidogrel Aspirin Stent International Cooperative Study (CLASSICS). Circulation. 2000;102:624-629.

15. Angiolillo DJ, Guzman LA, Bass TA. Current antiplatelet therapies: benefits and limitations. Am Heart J. 2008;156:S3-S9.

16. Angiolillo DJ, Fernandez-Ortiz A, Bernardo E, et al. Variability in individual responsiveness to clopidogrel. $J$ Am Coll Cardiol. 2007; 49:1505-1516.

17. Clinical Trials. gov. Protocol NCT00645918. GRAVITAS: Gauging Responsiveness With A VerifyNow Assay-Impact On Thrombosis And Safety. Available from: http://www.clinicaltrials.gov/ct2/show/NCT0 0645918?term=gravitas\&rank=1. Accessed Jun 9, 2010.

18. Wiviott SD, Braunwald E, McCabe CH, et al. Prasugrel versus clopidogrel in patients with acute coronary syndromes. $N$ Engl $J$ Med. 2007;357:2001-2015.

19. FDA Cardiovascular and Renal Drugs Advisory Committee Briefing Document. Efficient (Prasugrel) acute coronary syndromes managed by percutaneous coronary intervention. Available from: http://www.fda. gov/downloads/AdvisoryCommittees/CommitteesMeetingMaterials/ Drugs/CardiovascularandRenalDrugsAdvisoryCommittee/ucm 129219. pdf. Accessed Jun 10, 2010.

20. Serebruany VL. The TRITON versus PLATO trials: differences beyond platelet inhibition. Thromb Haemost. 2010;103:259-261.

21. van Giezen JJ, Humphries RG. Preclinical and clinical studies with selective reversible direct P2Y12 antagonists. Semin Thromb Hemost. 2005;31:195-204.

22. Husted S, van Giezen JJ. Ticagrelor: the first reversibly binding oral P2Y12 receptor antagonist. Cardiovasc Ther. 2009;27:259-274.

23. Anderson SD, Shah NK, Yim J, Epstein BJ. Efficacy and safety of ticagrelor: a reversible P2Y12 receptor antagonist. Ann Pharmacother. 2010;44:524-537.

24. van Giezen JJ, Nilsson L, Berntsson P, et al. Ticagrelor binds to human P2Y(12) independently from ADP but antagonizes ADPinduced receptor signaling and platelet aggregation. JThrom Haemost. 2009;7:1556-1565.

25. Wihlborg AK, Wang L, Braun OO, et al. ADP receptor P2Y12 is expressed in vascular smooth muscle cells and stimulates contraction in human blood vessels. Arterioscler Thromb Vasc Biol. 2004; 24:1810-1815.

26. Hogberg C, Svensson H, Gustaffson R, et al. The reversible oral P2Y12 antagonist AZD6140 inhibits ADP-induced contractions in murine and human vasculature. Int J Cardiol. 2010:142;187-192.

27. Bjorkman JA, Kirk I, van Giezen JJ. AZD6140 inhibits adenosine uptake into erythrocytes and enhances coronary blood flow after local ischemia or intracoronary adenosine infusion. Circulation. 2007; 116:II_28.

28. Teng R, Butler K. Pharmacokinetics, pharmacodynamics, tolerability and safety of single ascending doses of ticagrelor, a reversibly binding oral $\mathrm{P} 2 \mathrm{Y}(12)$ receptor antagonist, in healthy subjects. Eur J Clin Pharmacol. 2010;66:487-496.

29. Butler K, Mitchell PD, Teng R. No significant food effect on the pharmacokinetics of AZD6140, the first reversible oral P2Y12 receptor antagonist, in healthy subjects [abstract PI-39]. Clin Pharmacol Ther. 2009;85:S20.

30. Husted S, Emanuelsson H, Heptinstall S, Sandset PM, Wickens M, Peters G. Pharmacodynamics, pharmacokinetics, and safety of the oral reversible P2Y12 antagonist AZD6140 with aspirin in patients with atherosclerosis: a double-blind comparison to clopidogrel with aspirin. Eur Heart J. 2006;27:1038-1047.

31. Storey RF, Husted S, Harrington RA, et al. Inhibition of platelet aggregation by AZD6140, a reversible oral P2Y12 receptor antagonist, compared with clopidogrel in patients with acute coronary syndromes. J Am Coll Cardiol. 2007;50:1852-1856.
32. Gurbel PA, Bliden KP, Butler K, et al. Randomized double-blind assessment of the onset and offset of the antiplatelet effects of ticagrelor versus clopidogrel in patients with stable coronary artery disease: the ONSET/OFFSET study. Circulation. 2009;120:2577-2585.

33. Gurbel PA, Bliden KP, Butler K, et al. Response to ticagrelor in clopidogrel nonresponders and responders and effect of switching therapies. The RESPOND study. Circulation. 2010;121:1188-1199.

34. Peters G, Robbie G. Single-dose pharmacokinetics and pharmacodynamics of AZD6140 - an oral reversible ADP receptor antagonist. Haematologica. 2004;989(Suppl 7):14-15.

35. Peters GR, Butler KA, Winter HR. Multiple-dose pharmacokinetics (PK) and pharmacodynamics (PD) of the oral reversible, orally active ADP Receptor antagonist AZD6140. Eur Heart J. 2006;27(Suppl 1): P4556.

36. Butler K, Winter H, Mitchell P, et al. Pharmacokinetics and pharmacodynamics of AZD6140, the first reversible oral P2Y12 receptor antagonist, administered with aspirin [abstract 92]. J Clin Pharmacol. 2007:47:1204.

37. Butler K, Oliver S, Teng R. A mass balance study of major excretory routes and metabolic profile following an oral $\left[{ }^{14} \mathrm{C}\right]$ dose of AZD6140, the first reversible oral platelet $\mathrm{P} 2 \mathrm{Y} 12$ receptor antagonist, in healthy male subjects. Paper presented at: the 15th North American Regional Meeting of the International Society for the Study of Xenobiotics; October 12-16, 2008; San Diego, CA.

38. Butler K, Teng R. AZD6140, the first reversible oral platelet P2Y12 receptor antagonist, exhibits linear pharmacokinetics following multiple doses in healthy subjects, with greater and less variable inhibition of platelet aggregation compared with clopidogrel [abstract 562]. Can J Clin Phamracol. 2008;15:e684-e685.

39. Teng R, Butler K. AZD6140, the first reversible oral platelet P2Y12 receptor antagonist, has linear pharmacokinetics and provides near complete inhibition of platelet aggregation, with reversibility of effect, in healthy subjects [abstract 9]. Can J Clin Pharmacol. 2008; 15:e426.

40. Cannon CP, Husted S, Harrington RA, et al. Safety, tolerability, and initial efficacy of AZD6140, the first reversible oral adenosine diphosphate receptor antagonist, compared with clopidogrel, in patients with non-ST-segment elevation acute coronary syndrome: primary results of the DISPERSE-2 trial. J Am Coll Cardiol. 2007;50: 1844-1851.

41. Serebruany VL, Stebbing J, Atar D. Dyspnoea after antiplatelet agents: the AZD6140 controversy. Int J Clin Pract. 2007;61:529-533.

42. Husted S, van Giezen JJ. Dyspnoea and antiplatelet agents: revisited. Int J Clin Pract. 2007;61:1590; author reply 1591.

43. Serenbruany VL, Stebbing J. Dyspnoea after AZD6140: blaming the messenger. Int J Clin Pract. 2007;61:1590-1591.

44. Husted S, Harrington RA, Cannon CP, Storey RF, Mitchell P, Emanuelsson H. Bleeding risk with AZD6140, a reversible P2Y12 receptor antagonist, vs clopidogrel in patients undergoing coronary artery bypass grafting in the DISPERSE2 trial. Int $J$ Clin Pract. 2009;63:667-670.

45. Wallentin, L, Becker RC, Budaj A, et al. Ticagrelor versus clopidogrel in patients with acute coronary syndromes. $N$ Engl $J$ Med. 2009;361:1045-1057.

46. Cannon CP, Harrington RA. Comparison of ticagrelor with clopidogrel in patients with a planned invasive strategy for ACS (PLATO): a randomized double-blind study. Lancet. 2010;375:283-293.

47. James S, Akerblom A, Cannon CP. Comparison of ticagrelor, the first reversible oral P2Y(12) receptor antagonist, with clopidogrel in patients with acute coronary syndromes: rationale, design, and baseline characteristics of the PLATelet inhibition and patient Outcomes (PLATO) trial. Am Heart J. 2009;157:599-605.

48. van Giezen JJ, Berntsson P, Zachrisson H, Björkman JA. Comparison of ticagrelor and thienopyridine P2Y12 binding characteristics and antithrombotic and bleeding effects in rat and dog models of thrombosis/ hemostasis. Thrombosis Res. 2009;124:565-571. 
49. Storey RF, Bliden KP, Patil SB, et al. Incidence of dyspnea and assessment of cardiac and pulmonary function in patients with stable coronary artery disease receiving ticagrelor, clopidogrel, or placebo in the ONSET/OFFSET Study. J Am Coll Cardiol. 2010;56:185-193.

50. Tapp L. Role of ticagrelor in clopidogrel nonresponders: resistance is futile? Circulation. 2010;121:1169-1171.

51. Stone G. Ticagrelor in ACS: redefining a new standard of care? Lancet. 2010;375:263-265.

52. Moher D, Hopewell S, Schulz KF, et al. CONSORT 2010 explanation and elaboration: updated guidelines for reporting parallel group randomised trials. BMJ. 2010;340:c869.
53. Rosenstein R, Parra D. Letter to editor: ticagrelor versus clopidogrel in acute coronary syndromes. N Engl J Med. 2009;361:2385-2386.

54. Bhatt DL. Antiplatelet therapy: ticagrelor in ACS-what does PLATO teach us? Nat Rev Cardiol. 2009;6:737-738.

55. FDA Cardiovascular and Renal Drugs Advisory Committe Briefing Document. Ticagrelor for acute coronary syndromes, NDA 22-433. Available from: http://www. fda.gov/Advisory Committees/Committees Meeting Materials/Drugs/CardiovascularandRenalDrugsAdvisory Committee/ucm220190.htm. Accessed July 26, 2010.

56. Lagakos SW. The challenge of subgroup analyses: reporting without distorting. $N$ Engl J Med. 2006;354:1667-1669.

\section{Publish your work in this journal}

The Journal of Blood Medicine is an international, peer-reviewed, open access, online journal publishing laboratory, experimental and clinical aspects of all topics pertaining to blood based medicine including but not limited to: Transfusion Medicine; Blood collection, Donor issues, Transmittable diseases, and Blood banking logistics; Immunohematology; Artificial and alternative

\section{Dovepress}

blood based therapeutics; Hematology; Biotechnology/nanotechnology of blood related medicine; Legal aspects of blood medicine; Historical perspectives. The manuscript management system is completely online and includes a very quick and fair peer-review system. Visit http://www.dovepress.com/ testimonials.php to read real quotes from published authors.

Submit your manuscript here: http://www.dovepress.com/Journal-of-blood-medicine-journal 